\title{
$\mathrm{XV}$.
}

\section{Veber die periphere und centrale Anordnung der Sehnervenfasern und über das Corpus bigeminum anterius.}

\author{
Von
}

\section{Dr. Sigbert Ganser,}

Privatdocent an der Universität und Assistenzarzt an der. Kreis-Irienanstalt zu München.

(Hierzu Taf. VI. und VII.)

Seit die partielle Durchkreuzung der Sehnervenfasern im Chiasma der Säuger experimentell zur endgültigen Entscheidung*) gebracht ist, drängt sich die weitere Frage mehr in den Vordergrund, wie gekreuztes und ungekreuztes Bündel jnnerhalb des Tractus, des Chiasma und des Nervus opticus zu einander gelagert sind, in welcher Weise sich beide in der Netzhaut ausbreiten, speciell, welchen Antheil beide an der Versorgung der Macula lutea nehmen. Alle diese Fragen lösen sich bei genauer Untersuchung in mehrere Unterfragen auf; ihre Beantwortung interessirt in hohem Grade die topische Diagnostik der Gehirnkrankheiten, sie ist vielleicht von fundamentaler Bedeutung für die Lehre vom Sehen überhaupt. Insbesondere durch die glänzenden Versuche von H. Munk hat sich in neuester Zeit die Anschaung mehr und mehr Bahn gebrochen, dass die räumliche Anordnung der empfindenden Netzhautelemente sich im Centralorgane genau wiederhole; es würden sonach alle Fragen, welche ich Eingangs für den

*) v. Gudden, Ueber die Kreuzung der Nervenfasern im Chiasma nervor. opticor. v. Graefe's Arch. f. Ophthalm. XXV. 1.

W. Nic a ti, Comptes rendues de l'Acad. des sciences (Séance du 10. juin. 1878) und Archives de physiologie normale et patholog: 2. série V. 
peripheren Theil des Sehapparates aufgestellt habe, in gleicher Weise für das Sehcentrum gelten.

Nun ist, wie ich zeigen werde, die Netzhaut selbst einer fast unmittelbaren experimentellen Behandlung zugänglich, welche im Vereine mit nachfolgender anatomischer Untersuchung direct die periphere Anordnung der Nervenfasern und -Zellen zu erkennen gestattet und zudem von einem Theile der subjectiven und objectiven Fehlerquellen frei ist, welche dem central angelegten Thierexperimente und der nachfolgenden klinischen Beobachtung nothwendig anhaften müssen. Aus diesem Grunde habe ich den Angriffspunkt zunächst an die Peripherie verlegt, indem ich das ungekreuzte Opticusbündel isolirt zur Entwicklung kommen liess und dessen. Verbreitung in der Netzhaut studirte.

Die Detailfragen, welche ich mir bei dieser Untersuchung vorlegen musste, ergeben sich am besten, wenn ich den heutigen Stand unseres Wissens in diesem Punkte skizzire.

Ueber das gegenseitige Lageverhältniss des gekreuzten und ungekreuzten Bündels in Nerv, Chiasma und Tractus stehen einander zur Zeit zwei Ansichten gegenüber, deren eine, vorzugsweise durch v. Gudden vertreten, einen mehr weniger gesonderten Verlauf beider Bündel in den verschiedenen Abschnitten ihrer Bahn annimmt, während die andere, von Kellermann ${ }^{*}$ ) entwickelte, dahin resultirt, „dass die Fasern beider Nerven (unter partieller Durchkreuzung im Chiasma) in den Tractus innig mit einander verflochten sind; es existiren also keine „Fasciculi laterales“, d. h. Gruppen von Fasern, welche am lateralen Rande des Chiasma von einem Nervus zum entsprechenden Tractus zieben; es existirt überhaupt keine Nervenfasergruppe, welche durch das ganze Chiasma hindurchzöge, ohne sich mit anderen Fasern zu verflechten, mag sie nun im Nervus und Tractus auf derselben Seite liegen oder von einer zur andern überziehen“. Diese Ansicht Kellermann's stützt sich auf die Untersnchung eines Falles von totaler Atrophie des einen und partialer des anderen Sehnerven vom Menschen; sie wird von Seiten der Ophthalmologen $*$ ) als besonders geeignet gefunden, die klinischen Beobachtungen von homonymer und heteronymer Hemianopsie aus einer einzigen Ursache zu erklären.

*) Kellermann, KI. Mon. f. Augenh. XVIII. Beilageheft p. 38.

*) Kellermann a. a. 0. p. 41 ff,; Wilbrand, Ueber Hemianopsie und ihr Verhältniss zur topischen Diagnose der Gehirnkrankheiten. Berlin 1881, p. 39 und 53. - L. Ma uth ner, Gehirn and Auge p. $427 \mathrm{ff}$. 
Was speciell die Ansicht v. Gudden's betrifft, so hat derselbe ${ }^{*}$ ) angegeben, das ungekreuzte Bündel verlaufe beim Hunde so, dass es vom oberen Rande des Tractus kommend, das gekreuzte Bündel des entgegengesetzten Tractus kreuze und an die mediale Seite des gleichseitigen Nerven trete. Diese Deutung normal-anatomiscber, in besonders günstiger Ebene hergestellter Schnittpräparate fand eine Stütze in der von Bumm zuerst beobachteten auffallenden Configuration des Chiasma von Mustela Erminea; eine eigentliche Beweiskraft erlangt sie aber erst durch die Untersuchung eines Falles von einseitiger totaler Opticusatrophie, welche v. Gudden**) zu machen Gelegenheit hatte. Der rechte Nerv. opt. war total atrophisch und liess sich als solcber durch das Chiasma bis in den Tractus optic. verfolgen; dadurch trat das ungekreuzte Bündel des linken Nervus optic. als weisser Wulst im Chiasma hervor, welcher genau den oben vom Hunde beschriebenen Verlauf nahm, so dass es an den medialen Rand des linken Nerven zu liegen kam; innerhalb der Tractus bildeten zwar gekreuztes und ungekreuztes Bündel eigene Zonen, allein diese waren nicht scharf geschieden und es fanden sich in den atrophischen Segmenten beider Tractus Nervenfasern, welche als zerstrente Elemente des anf der betreffenden Seite erhaltenen Bündels angesehen wurden. Einen iw Wesentlichen gleichen Befund hatte schon früher Baumgarten ${ }^{* * *}$ ) erhalten, und auch die Untersuchungen, welche Purtscher $\dagger$ ) an 6 einseitigen Totalatrophien des Nervus opticus anstellte, ergaben den v. Gudden'schen ähnliche Resultate.

In welchem Lageverhältniss gekreuztes und nngekreuztes Bündel innerhalb des Nervus optieus bis zum Bulbus verlaufen, darüber ist nichts Sicheres bekannt; doch geht aus den Untersuchungen von

*) v. Gudden, Ueber die Kreuzung der Nervenfasern im Chiasma nervorum opticor. F. Graefe's Arch. f. Ophthalm. XXV. 1. p. 31.

Ich lasse hier die frühere Angabe v. Gudden's (. . Graefe's Arch. f. Ophthalm. p. 255), „die sich kreuzenden Bündel liegen vorzugsweise in der unteren, die sich nicht kreuzenden vorzugsweise in der oberen Hälfte des Chiasma", ausser Betracht, weil sie sich blos auf die Untersuchung einer normal-anatomischen Schnittreihe durch das menschliche Chiasma stützt.

**) v. Gudden, Ueber die Irreuzung der Nervenfasern im Chiasma Nervorum optic. v. Graefe's Arch. f. Ophthalm. XXV. 1.

**s) Baumgarten, Zur sog. Semidecussation der Opticusfasern. Ctbl. f. d. med. W. 1878 No. 31.

†) Purtscher, Deber Kreuzung und Atrophie der Nervi und Tractus optici. v. Graefe's Arch. f. Ophthalm. XXVI. 2. 
Kellermann*) und Samelsohn**) hervor, dass die Fasern im Allgemeinen ihre gegenseitige Lage während jenes Verlaufes sehr erheblich verändern können.

Weiter vorgeschritten sind unsere Kenntnisse über die Verbreitung beider Bündel in der Netzhaut selbst. Seit die Partialkreuzung im Chiasma ausser Frage gestellt ist, sind die Fälle von homonymer lateraler Hemianopsie in Folge der Läsion eines Tractus optic. beweisend dafür, dass das ungekreuzte Bündel sich in der temporalen, das gekreuzte in der nasalen Hälfte der Netzhaut ausbreitet; dagegen liefert das bis jetzt vorliegende Material keinen sicheren Anhaltspunkt dafür, ob die Verbreitungsbezirke beider in scharfer, vertical die Fovea centralis durchschneidender Linie sich von einander scheiden, oder ob die ganze Macula Intea von beiden Bündeln versorgt wird. Für die erstere Annahme scheinen die Fälle von homonymer Hemianopsie mit vertical durch den Fixationspunkt gehender Trennungslinie zu sprechen und für die zweite jene Fälle***), in welchen zwischen erhaltener und fehlender Gesichtsfeldhälfte eine schmale Zone stumpfer Empfindung vorhanden war.

Nächst den klinischen Erfahrungen am Menschen kommen für die Frage der Verbreitung beider Opticusbündel in der Netzhant die Versuche von $H$. Munk $\dagger$ ) in Betracht. Indem H. Munk die Zugehörigkeit beider Arten von Sehnervenfasern zu einem Sehcentrum ausschliesslich vom Bau des Chiasma abhängig macht, gewinnt er aus seinen Experimenten die Ueberzeugung, dass beim Hunde das ungekreuzte Bündel sich nur in der äussersten nasalen Partie der Retina ausbreite, dass sein Verbreitungsbezirk bei verschiedenen Hunderacen um so weiter nasalwärts sich ausdehnt, je geringer die Divergenz der Augen sei, in den günstigsten Fällen aber nicht mehr als ein Viertel der Retina ausmache. Seine Grenze würde demnach die Stelle des directen Sehens nicht erreichen. Beim Affen dagegen würde der verticale Meridian, welcher durçh die Fovea centralis geht, die Grenzlinie für die Ausbreitung des ungekreuzten Bündels abgeben.

Angesichts der grossen Schwierigkeiten, mit welchen die subtile Beobachtung von Thieren in Bezug auf die Ausdebnung des Gesichts-

*) Kellermann a. a. 0. p. 35.

*) Samelsohn, Centralbl. f. d. med. W. 1880. 418.

***) Wilbrand a. a. O. p. $8 \mathrm{ff}$. und Hirschberg (Nagel's Jahresbericht 1876,79$)$.

†) H. Munk, Verhandl. der Physiol. Gesellsch. zu Berlin, Jahrg. 1878 bis 79 No. 18 und $1880-81$ No. 15 und 16 . 
feldes verknüpft ist, muss ich gestehen, dass ich es durch die Munkschen Experimente nicht für ausgemacht halte, dass die Verbreitungsbezirke beider Bündel mit scharfer Linie sich von einander scheiden. Es wäre denkbar und die oben erwähnten klinischen Beobachtungen würden dies nicht als eine willkürlich ersonnene Möglichkeit erscheinen lassen, dass auch beim Affen das Netzhautcentrum von beiden einander durchflechtenden Bündeln versorgt würde, dass aber gleichwohl der Nachweis dieses Verhältnisses bei Thieren auch einem so trefflichen Beobachter wie Munk unmöglich wäre. Es dürfte schon beim Affen kaum möglich sein, zu ermitteln, ob nach einer Totalexstirpation z. B. des linken Sehcentrums die nächst der Fovea centralis temporalwärts gelegene Partie der linken Netzhaut nicht noch einen Rest von erhaltenem, weniger scharfem Sehvermögen besitzt, und $o b$ in gleichem Falle nicht in der entsprechenden temporalen Partie der rechten Netzhaut die Sehschärfe herabgesetzt sei. Beim Hunde müsste ein ähnlicher Nachweis noch viel schwieriger sein als beim Affen.

Einen mehr directen Beitrag zur vorliegenden Frage lieferte Bumm*), indem er die Retina eines Kaninchens untersuchte, bei welchem v. Gudden das ungekrenzte Bündel isolirt dargestellt hatte. Es fand sich, dass dasselbe sich ausschliesslich auf der temporalen Netzhautfläche ausbreitet, während die Vergleichung mit einer normalen Kaninchenretina ausserdem noch den evidenten Nachweis lieferte, dass das gekreuzte Bündel nicht nur in der nasalen, sondern auch in der oberen und unteren Partie der Retina sich vertheilt und ausserdem noch Fasern zum temporalen Bündel schickt. Gekreuztes und ungekreuztes Bündel participiren also beim Kaninchen an der Zusammensetzung des temporalen Netzhautbündels, ersteres mit 0,159 Mm., letzteres mit $0,051 \mathrm{Mm}$. im senkrechten Durchmesser. Eine der Fovea centralis ähnliche Vorrichtung konnte Bumm in der Netzhant des Kaninchens nicht finden; somit wurde auch die mehrfach erwähnte Detailfrage in Bezug auf deren Faserversorgung nicht in Betracht gezogen.

Ich habe als Versuchsthier die Katze gewählt und zwar aus verschiedenen Gründen. Einmal ist sie eines unserer intelligentesten Hausthiere, ihr Grosshirn ist gut entwickelt und steht, soweit ich nach einfacher Schätzung anzugeben vermag, an Windungsreichthum und relativem Gewichte dem des Hundes nicht nach. Was sie aber besonders zu Versuchen über den Gesichtssinn geeignet macht, das

*) Dieses Archiv Bd. XI. p. 264. 
ist die hohe Entwicklung, welche gerade der letztere bei der Katze erreicht. Sie ist in dieser Hinsicht entschieden vor dem Hunde, der mehr mit dem Geruche operirt, bevorzugt; die Katze ist ein Gesichtsund Gehörsthier und steht insoferne dem Menschen unstreitig näher als der Hund. Dies leuchtet ganz besonders ein, wenn man die Grösse des binocularen Gesichtsfeldes bei Hund und Katze mit einander vergleicht: während die Augenaxen des Hundes nicht unbeträchtlich divergiren, haben die der Katze eine Stellung zu einander, welche von der menschlichen nicht sehr verschieden ist; ihr binoculares Gesichtsfeld ist gross und dem entspricht, wie aus den Messungen v. Gudden's hervorgeht, ein auffallend grosses ungekreuztes Bündel. Der guten Entwicklung des Gesichtssinnes ist es ferner zuzuschreiben, dass die Katzen bei der Lebhaftigkeit ihres Temperamentes, namentlich in der Jugend sehr prompt nicht nur einem Gegenstande, den man in ibrem Gesichtsfelde bin- und herbewegt, folgen, sondern sobald und solange sie desselben ansichtig sind, ihn $z u$ haschen suchen, indem sie danach springen. Ein weiter unten mitzutheilendes Experiment wird diesen Vorzug besonders illustriren.

Während der anatomischen Untersuchung bin ich auf einige Eigenthümlichkeiten der Katzenretina aufmerksam geworden, welche noch mehr als die angedeuteten Eigenschaften des Thieres gestatten dürften, die Versuchsergebnisse, welche daran gewonnen sind, direct auf den Menschen zu übertragen. Ich will sie gleich hier anknüpfen.

\section{Zur Anatomie der normalen Katzenretina.}

Die Eintrittsstelle des Sehnerven in die Netzhaut liegt bei der Katze um ein ziemlich Beträchtliches nach unten von einer den Bulbus halbirenden Horizontalebene und zwar innerhalb des nasalen Quadranten; die Papille hat eine querovale Configuration.

Von Angaben über die Dicke der Netzhaut und der einzelnen Schichten sehe ich ab, da sie nur einen Werth haben, wenn sie auf zahlreichen Messungen an verschiedenen Individuen beruhen. Mich interessirt hier vorzugsweise das Verhalten der Nervenfaser- und Ganglienzellenschichte.

Die Nervenfasern des Opticus verlieren, wie dies bei den meisten Säugern der Fall zu sein pflegt, bei ihrem Durchtritte durch die Lamina cribrosa ihre Markscheiden und verbreiten sich im Allgemeinen von der Papille aus radienförmig nach allen Seiten. Diese allgemeine Anordnung erleidet an einzelnen Stellen näher zu beschreibende Modificationen. Es gehen zämlich. nach oben und unten mehr. Fasern als nach den Seiten, und insbesondere ist die untere Partie reichlich mit Fasern versehen. Sie bilden im Umkreiso der Papille mit Ausnahme einer Stelle eine continuirliche eigene Schicht, deren Dicke gegen die Peripherie ganz allmälig abnimmt; je mebr dies eintritt, 
um so mehr verliert dioselbe den Charakter oiner selbstständigen Schichte, sondern verläuft innerhalb der Ganglienzellenlage, und man kann, wenn man in einem Netzhautquerschnitte die Faserlage in ihrem Längisverlaufe übersieht, bemerken, wie sie sich peripheriewärts allmälig in einen Faden auszieht, der immer dünner werdend zwischen den Ganglienzellen sich verliert. Hat man die Fasern senkrecht zu ihrem Verlanfe getroffen, so sieht man sie in. grösseren und kleineren Bündeln zusammenliegen. Vergleicht man auf Querschnitten, die in der Horizontalen durch die Papille gelegt sind, die Nervenfaserschichten beider Seiten miteinander, so ist auffallend, dass man nasalwärts dasselbe Bündel immer auf eine längere Strecke in der Längsansicht verfolgen kann, wahrend anf der temporalen Seite die Bündel alsbald in Schrägschnitten erscheinen. Wenn schon aus diesem constanten Befunde hervorgeht, dass die Fasern nasalwärts genau radienförmig, temporalwärts dagegen bogenförmig verlaufen, so tritt dies noch viel deutlicher in Verticalschnitten hervor. Verfolgt man eine Serie von solchen von der Peripherie gegen die Opticnspapille zu, so trifft man zuerst ein continuirlich über den ganzen Schnitt ausgebreitetes Lager von Bündeln quergeschnittener Fasern; an einer gewissen Stelle der Reihe angekommen, findet man plötzlich die Nervenfaserschicht unterbrochen und in der Lücke die Ganglienzellenschichle unmittelbar an der Membr. limitans interna anliegend; diese Lücke wird gegen die Opticuspapille zu etwas grösser, dann wieder kleiner und füllt sich wenig nach Aussen ron der Papille wieder ganz mit Nervenfaserbündeln aus, die aber durch ihre verhältnissmässige Schwäche erkennen lassen, wo man in den nächsten Schnitten die Papille zu erwarten hat. Die Nervenfasern verlaufen demnach in der Netzhaut der Katze in derselben Weise, wie wir es durch die Untersuchungen von Kölliker*), Liebreich"*) and Michel ${ }^{* * *}$ ) yom Mensehen wissen.

Die Aehnlichkeit im Bau der Retina geht aber noch woiter und erstreckt sich namentlich auf die Ganglienzellenschichte. Jene Stelle, welche ich als von Nervenfasern entblösst beschrieben habe, ist durch eine besonders stark entwickelte Ganglienzellenschichte ausgezeichnet. In horizontalen Querschnitten, welche durch die oberen Ebenen der Opticuspapille (nahe dem Rande derselben) gelegt sind, erkennt man schon mit blossem Auge in der temporalen Hälfte eine Verdickung der Netzhaut, welche in Form eines kleinen Hügels vorspringt, wie dies Fig. 1 wiedergiebt. Dieser Hügel hat sowohl im horizontalen wie im verticalen Querschnitte die gleiche, symmetrisch nach beiden Seiten abfallende Contur, so dass man sagen kann, dass er sich auf kreisförmiger Basis erhebt. Seine Entfernung vom Rande der Papilla nervi optici scheint einigermassen individuellen Schwankungen zu unterliegen; ich habe

Kölliker, Handb. der Gewebeiehre. V. Aufl. p. 676.

**) Zehender, Klin. Monatsblätter für Augenheilk. Jahrg. VII. 1869. p. 457 .

***) Michel, Ueber die Ausstrahlungsweise der Opticusfasern in der menschl. Retina, - in „Beiträge der Anat. und Physiol." L. Ludwig gewidmet. 1874. Leipzig. 
bei einem Individuum vom Rande der Papille bis zum Scheitel des Hügels 2,4 Mm., bei einem anderen 2,8 $\mathrm{Mm}$. gemessen. Man kann sich leicht überzeugen, dass der Hügel vorzugsweise durch eine Verdickung der Ganglienzellenschichte entsteht, welche von Nervenfasern gänzlich entblösst, direct an die Membr. limitans anstösst und aus einer vierfachen Lage dicht an einander gedrängter Elemente bestẹht. Die Schichtung der Ganglienzellen verliert sich nach den Seiten hin allmälig, ist zuletzt noch eine doppelte und geht dann in die einfache Lage über, welche in der ganzen übrigen Retina die Nervenzellen bilden. Eine zwei-bis vierfache Zellenlage findet sich demnach in einem Kreise, der um den Scheitel des Hügels mit 1,4 Mm. Radius beschrieben ist. Eine Fovea centralis ist nicht vorhanden, daher die Müller'schen Stützfasern nicht, wie beim Menschen schief, sondern gerade radiär verlanfen, wie sonst überall. Was das Verhalten der übrigen Schichten an dieser Stelle betrifft, so vermag ich detaillirte Angaben darïber nicht zu machen, doch ist sicher kein augenfälliger Dickenunterschied im Vergleich zu den übrigen Partien der Reina vorhanden. Ueber die Zusammensetzung der Stäbohen- und Zapfenschichte sind weitere Untersuchungen (Flächenansichten) nothwendig, da meine Schnittpräparate mich zu einer bestimmten Ansicht darüber nicht gelangen liessen.

Man bat hier eine histologisch differenzirte umschriebene Partio vor sich, welche die wesentlichsten Charalitere einer centralen Sehstelle besitzt und welche ich als solche anzusprechen kein Bedenten trage. H. Mülle $\mathrm{r}^{*}$ ) hat angegeben, dass bei Säugethieren wenigstens eine "Area centralis" vorkomme, welche sich dem Bau des gelben Flecks nähert und durch einen ähnlichen Verlauf der Centralgefässe, wie beim Menschen, kenntlich gemacht ist. Weitere Mittheilungen, welche er in Aussicht stellte, sind nicht erfolgt. Der Name Area centralis wird am besten beibehalten werden.

Nach dem Verlaufe der Nervenfasern, wie ich ihn beschrieben babe, wird man annehmen müssen, dass dieselben in der gleichen Weise an die Ganglienzellen der Area centralis der Katze $\left.{ }^{* *}\right)$ herantreten wie beim Menschen an die Macula lutea, $d . h$. vorzugsweise in bogenförmigem Verlaufe von unten und oben her; einige Präparate besitze ich, in welchen sich die von der Papille in radiärer Richtung ausstrahlenden Fasern als dünner Faden bis in die

*) H• Müller, Anatomie und Physiolog. des Auges p. 138.

**) Michel giebt (in d. Beiträgen zur Anat. und Physiolog. p. 62) an, dass in der Retina des Pferdes, Schweines, Ochsen und Schafes von einem bogenförmigen Verlaufe im Sinne der Umkreisung einer Macula nirgends etwas zu entdecken ist, dagegen fand Koelliker (Entwicklungsgesch. d. Menschen u. d. höheren Thiere p. 685) „bei Schafembryonen von $22 \mathrm{Mm}$., deren Opticusfaserung schon ganz gut ausgebildet war, an der Eintrittsstelle des Sehnerven in's Auge, und zwar an der untern Seite cine längliche schmale Spalte, die die Nervenfasern bogenförmig nmgaben, die allerdings den Gedanken nahe legte, dass hier ein Vorstadium der Area centralis der Sänger gegehen war". 
Mitte der Area verfolgen lassen. Fig. 2 ist bei starker Vergrösserung einem Schnitte aus der Höhe der Area centralis entnommen.

Im Allgemeinen möchte ich noch hervorheben, dass die Katzenretina für das Studium ein sehr günstiges Object ist, weil sie eire ausserordentliche Differenzirung der zelligen Elemente und namentlich ein Hervortreten der nervösen gegenüber den bindegewebigen Substanzen zeigt. Ich habe Präparate, in welchen die Structur derselben in ihren Grundzïgen mit wahrhaft schema-. tischer Deutlichkeit zu sehen ist. Zur Präparation habe ich mich durehgehends 2 procentiger Osmiumsäure bedient, deren Einwirkung ich die Netzhäute durch $3-4$ Stunden aussetzte; geschnitten wurde unter Allohol mit dem Forelschen Mikrotome.

Um das ungekreuzte Bündel ganz isolirt darzustellen, bediente ich mich einer Nethode, welche ich schon früher*) angegeben habe, und welche sich durch die möglichste Schonung der nicht in Betracht kommenden Hirntheile empfiehlt. Ich habe einem Kätzchen A. am dritten Tage nach der Geburt das linke Auge enucleirt, bin dann mit einer spitzen Pincette durch das Foramen optic. eingedrungen und habe unmittelbar neben der Mittellinie den gleichseitigen Tractus opticus zu durchreissen gesucht. Im Falle des Gelingens mussten durch diese Operation die gekreuzten Bündel beider Augen, das nngekreuzte des linken und die ganze Commissura infer. zu Grunde gehen und erhalten konnte sich nur das ungekreuzte Bündel des rechten Auges. Die Operation, so einfach sie scheint, gelingt nicht immer; doch ist sie bei der Katze immerbin leichter, als beim Ka. ninchen wegen der geringeren Distanz zwischen Chiasma und Foramen opticum. Ziemlich sicher geht man bei der Katze, wenn man die Pincette genau in der halben Höhe der medialen Orbitalwand horizontal nach hinten führt. Die Lidspalte wird nach der Operation vernäht.

Das Kätzchen vertrug die Operation gut und zeigte zunächst nichts Besonderes; doch verliess es später, wie dies die jungen Katzen zi thun pflegen, das Lager und begann später seine Gehversuche anzustellen. Als dies endlich geschah, bemerkte ich, dass das Thierchen das rechte Hinterbein ein wenig nachzog**); doch verlor sich dies

*) Vgl. v. Gudden in v. Graefe's Arch. f. Ophth. XXV., 4. p. 243.

*) Es ist hier öfters bemerkt worden, dass bei der Ausführung obiger Operation die Spitzen der Pincette sehr leicht von der Basis des Gehirns aus in die innere Kapsel dringen, die gerade hier der Oberfläche nahe liegt; vgl. unten den Sectionsbericht der Katze A. 
innerhalb einiger Wochen vollständig. Dagegen erhielt sich eine andere Eigenthümlichkeit, welche auch für die Ursache des späten Eintretens der Gehversuche einen Fingerzeig gab: das Thier trug nämlich den Kopf stets nabe am Boden, schnäffelnd und tastend, so dass man in der ersten Zeit zweifeln konnte, ob es überbaupt sah; indessen überzeugte ich mich davon durch mancherlei Proben: wenn man es z. B. auf einen Tisch setzte, so wählte und fand das Thier stets die Stelle, welche zum Hinunterspringen die bequemste war, etwa in der Nähe eines Stuhles, den es als Passage benutzte; später wurde es immer deutlicher, dass das Thier sah und sein Gesicht ausbildete, indem es von seinem Aufenthaltsorte aus Spaziergänge durch den Garten unternahm, auf ganz fremdem Terrain sich ziemlich gut orientirte und stets den Rückweg fand.

Psychisch war A. von einer normalen Katze himmel weit verschieden; man vermisste daran die Lebendigkeit der Bewegung und die Lust am Spielen, welche diese Thiere sonst auszeichnen und je mehr es erwuchs, um so deutlicher wurde der psychische Defect; das Thier hatte kein Temperament, liess sich von jedem Beliebigen anfassen und forttragen und obzwar es eine grosse Gefrässigkeit an den Tag legte, war es nicht im Stande, eine Beute zu erhaschen, ein Umstand, durch welchen es sich sehr von der unten zu beschreibenden, gleichfalls invaliden Katze B. unterschied; auch war es schwer, das Thier auf wenige Minuten für etwas zu interessiren, was nur auf das Gesicht wirkte; ein weisser Ball, vor dem Auge im Kreise vorbeigeführt, erregte wohl die Aufmerksamkeit auf kurze Zeit und rief auch Verfolgungsbewegungen hervor, doch dauerte dies nie lange, und selbst wenn man den Papierball über den Boden schleifend das Gehör mit erregte, dauerte das Interesse nicht lange. Das Thier war nach jeder Richtung viel blödsinniger, als eine Katze C., welcher ich fast eine ganze Hemisphäre exstirpirt hatte, ein Umstand, der mich besonders darüber belehrte, wie sehr die Katzen in ihrer psychischen Entwicklung vom Gesichtssinne abhängig sind*). Die Augenstellung war von der normalen nicht abweichend.

Bei dieser psychischen Beschaffenheit des Thieres war es natürlich schwer, über die Grenzen des Gesichtsfeldes ein exactes Urtheil zu gewinnen; doch war die folgende Reaction desselben eine ganz constante: wenn ich einen Papierball geräuschlos an schwarzem Fa-

*) Es liegt nahe hier an die Imbecillität taubstumm geborener Menschen zu denken, die keinen für sie besonders angepassten Unterricht genossen haben. 
den schwingen liess, so dass er um die Katze herum einen Kreis beschrieb, so machte dieselbe niemals den geringsten Versuch, ihn zu haschen, falls er im Sinne eines Uhrzeigers sich bewegte; dagegen geschah dies oft und mit einiger Treffsicherheit, wenn er in entgegengesetzter Richtung schwang. Aus diesem Versuche, der durch die Katzen $B$, und $\mathrm{C}$. eine besondere Bedeutung erhält, habe ich geschlossen, dass das Thier blos mit der temporalen Retinahälfte sehen könne und zwar aus den Gründen, welche ich unten erörtern werde.

Herr Dr. Eversbusch hatte die Freundlichkeit, eine ophthalmoskopische Untersuchung des Kätzchens vorzunehmen und mir folgenden Befund darüber zu notiren. Für Beides meinen besten Dank.

Rechtes Auge (links Abulbie): Bei der Untersuchung im ungekehrten Bilde machte es zuerst den Eindruck, als ob nur der mediale untere Quadrant der Opticuspapille sein normales Aussehen bewahrt habe; dagegen schien der mediale obere Quadrant intensiv weisslich verfärbt und die äussere Papillarhälfte von blass-grauröthlichem Aussehen.

Bei der Untersuchung im anfrechten Bilde nach vorgängiger Atropinisation erwies sich indessen dieser Befund als Täuschung, indem das anscheinend normale Colorit des medialen unteren Quadranten dadurch bedingt war, dass abweichend von der gewöhnlichen Ursprungsweise der Retinalgefässe auf diesem Quadranten nicht weniger denn 5 ( 3 Venen, 2 Arterien) zusammengedrängt waren; in Wirklichkeit hatte auch der mediale untere Quadrant annähernd das gleiche Aussehen, wie der mediale obere; der letztere von intensiv weisslicher Färbung liess nur hie und da eine zarte Tüpfelung gewahren: die netzförmige Zeichnung der Lamina cribrosa ist bis über die Mitte der Papille erkennbar und erstreckt sich auch etwas über die äussere Papillarbälfte nach aussen, oben etwas mehr als unten; der Uebergang der pathologisch veränderten Partion zu den normalen findet in allmäliger Weise statt, indem die Bündel der Lamina cribrosa sich allmälig verjüngend in den lateralen Papillarabschnitt übergehen.

A. wurde, vollständig ausgewachsen, im Alter von 9 Monaten getödtet; die Section ergab Folgendes, was durch die Fig. 3 durchaus naturgetreu illustrirt wird:

Der Stumpf des linken Nervus opticus bildete ein glashelles durehsichtiges Stäbchen, das sich in doppeltchromsaurer Kalilösung sehr rasch ganz grau färbte; von seiner Grösse giebt am besten die unmittelbare Anschauung der Abbildung, deren Masse mit einem feinen Zirkel genommen sind, eine Vorstellung; einer mikroskopischen Untersuchung habe ich denselben nicht weiter unterzogen, da Niemand an der Totalatrophie desselben zweifeln wird; in Bezug auf das Verhalten eines der gleichen Behandlung ansgesetzt gewe- 
senen Nerven verweise ich auf die Untersuchungen v. Gudden's*). Von diesem Nervenstumpfe ging eine zarte bindegewebige Membran medialwärts, welche sich mit der grauen Substanz des Tuber ciner. verband und so dünn wurde, dass sie in der Mittellinie als eigenes Gebilde nicht mehr zu erkennen war; sie stellte den Rest des Chiasma dar. Unmittelbar lateral vom linken Nerv zeigte sich in der Substantia cinerea anterior eine halbmondförmige 2-3 Mm. lange Lücke mit scharf geschnittenen Rändern, der Angriffspunkt der Pincette. Auf der linken Seite war der Tractus opticus spurlos verschwunden, nicht ein Hauch eines bindegewebigen Restes deutete die Stelle an, wo er gelegen hatte. Speciell erwähne ich noch, dass auch die Commissura inferior und die Meynert'sche Commissur daselbst vollständig fehlten. Wenn ich in der idealen Richtung des fehlenden Tractus opticus lateralwärts gehe, so finde ich ein weisses Faserbündel, welches rom lateralen Rande des Hirnschenkelfusses aus hakenförmig um den medialen Kniehöcler herumbiegt, mit einem dentlichen Marklager den lateralen (oberen bei der Katze) Kriehöcker überzieht und noch bis zum vorderen Zweihügel, ganz der Richtung des Tractus opticus folgend, verläuft. Dieses Bündel normalerweise vollständig vom Tractus bedeckt, und davon unzertrennlich, ist ein von der Retira unabhängiger Bestandtheil desselben, dessen Existenz v. Gudden ${ }^{* *}$ ) zuerst behauptet und welchen ich ${ }^{* * *}$ ) zuerst beim Kaninchen isolirt dargestellt habe, es ist v. Gudden's Hemisphärenbündel des Tractus opticus, dasselbe, welches ich, soweit es zum lateralen Kniehöcker geht, „Stiel des lateralen Kniehöckers" genannt habe.

Auf der rechten Seite dagegen war ein ansehnlicher markweisser Nerv, welcher in der Gegend des Chiasma in scharfem Winkel umbog und als Tractus opticus seinen weiteren normalen Verlauf nahm. Zweierlei erregte an diesem Objecte meine Verwunderung: die Grösse des erhaltenen ungekreuzten Bündels und der scheinbare Mangel eines vom gekreuzten Bündel zurïckgebliebenen bindegewebigen Restes; von einem solchen war hier mit der Lupe nichts zu sehen. Die Commissura infer. fehlte natürlich sowohl in der Gegend des Chiasma als im Tractus opticus dexter, dagegen schien von der Meynert'schen Commissur ein Rest am hinteren Rande desselben zu Tage zu treten und sich im Hirnschenkelfusse zu verlieren, was im Vereine mit der totalen Atrophie auf der anderen Seite dafür sprechen würde, dass sie keine Commissur, sondern eine Krenzung ist. Im weiteren Verlaufe bietet der Tractus opticus dexter nichts Auffallendes dar, als dass er das Corpus geniculatum mediale ganz frei zu lassen scheint.

Ein Vergleich der primären Centren beider Seiten ergiebt, dass der rechte laterale Kniehöcker grösser ist als der linke, sein Marküberzug dichter,

*) In v. Graefe's Archiv f. Ophthalm. XXV. 1. p. 26 ff.

**) In diesem Archiv Bd. II. p. 714 und 716 .

***) v. Gudden in v. Graefe's Archiv f. Ophthalm. XXV., 4. p. 242 und S. Ganser, Vergleichende anatomische Studien des Gehirns des Maulwurfs im Morphol. Jabrbuch Bd. VII. p. $705 \mathrm{ff}$. 
dicker und in Folge dessen intensiver weiss, und dass auch der rechte vordere Zweihügel bei gleicher Circumferenz slärker gewölbt ist, als der linke.

Vom Tractus peduncularis transversus*) ist auf der linken Seite nur eine Andeutung vorhanden, die den lateralen Rand des Hirnschenkelfusses nicht überschreitet, während der gleiche Faserzug rechts zwar nicht normal, aber doch stärker ist als links und wreiter medialwärts sich erstreckt.

Noch zwei andere, nicht auf den Sehapparat bezügliche Befunde, als Folgen der Operation erwähne ich der Vollständigkeit halber: einmal eine Abflachung und undeutliche Abgrenzung des medialen Theiles vom Pes peduneuli sinistri leicht erklärlich durch die erfahrungsmässig begründete $\Lambda \mathrm{n}$ nahme, dass die Pincette ein wenig in die linke innere Kapsel eingedrungen sei - ferner auf der rechteı Seite eine höchst auffällige Atrophie des Corpus mammillare und zwar, wie es scheint, sowohl des mediales Ganglion (Ursprung des Vicq d'Azyr'schen Bündels) als auch des lateralen (Ursprung des Pedunculus corporis mammillaris**). Ueber die Ursachen dieser Atrophie sind von der Untersuchung der Schnittreihen interessante Aufschlüsse zu erwarten; einstweilen enthalte ich mich darüber aller Muthmassungen.

An den Grosshirnhemisphären der Katze A. habe ich weder beim Vergleiche beider Seiten mit einander, nöch beim Vergleiche mit einem anderen Katzenhirne Differenzen in der Entwicklung der Windungen constatiren

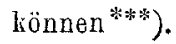

Die mikroskopische Untersuchung hat sich zunächst mit dem Tractus, der Chiasmagegend und den Nerven, - sodann mit dem Durchschnitt des Nerven durch die äusseren Augenhäute in die Netzhaut und mit der letzteren selbst zu befassen.

Um der ersteren Aufgabe gerecht zu werden, habe ich den Tractus $2,5 \mathrm{Mm}$. hinter dem Winkel, welchen er mit dem Nerven bildet, quer durchtrennt, mit der Chiasmagegend und dem Nerven yom Tuber losgelöst, in toto mit Carmin gefärbt und nach Alkoholhärtung in eine Schnittreihe zerlegt. Die Untersuchung derselben hat Folgendes ergeben:

Ein exacter Querschnitt durch den Tractus $2 \mathrm{Mm}$. nach Aussen von dem erwähnten Winkel lässt nicht die Spur einer Anhäufung von Bindesubstanz

*) Vgl. über dessen Abhängigkeit von der Retina: v. Gudden in diesem Archiv Bd. XI. Heft 2.

*) Vgl. v. Gudden, Beitrag zur Kenntniss des Corpus mammillare und der sogenannten Schenkel des Fornix, dieses Archiv Bd. XI. Heft 2. p. 6 sowie S. Ganser, Vergl. anatom. Studien über d. Gehirn des Maulwurfs im Morph. Jahrbuch Bd. VII. p. $691 \mathrm{ff}$.

*:**) Vgl. Mittheilungen der morpholog. - physiolog. Gesellschaft zu München im Aerztlichen Intelligenz-Blatt 1880 No. 9, sowie

F'ürstner, Weitere Mittheilungen über den Einfluss einseitiger Bulbuszerstörung auf die Entwicklung der Hirnhemisphären. Dieses Archiv Bd. XII. p. 611 . 
erkennen, welche als Residuum des atrophirten gekreuzten Bündels aufgefasst werden könnte; weder für die Lage des letzteren, noch der Commissura infer. ist die mindeste Andeutung gegeber; beide sind spurlos verschwunden, ein Beweis, wie wenig Bindegewebe im Tractus der jungen Katze vorhanden war. Von der Configuration dieses Querschnittes giebt Fig. 4 bei etwa 8 facher Vergrösserung ein Bild, welches also ausschliesslich als Querschnitt des ungekreuzten Bündels im Tractus aufzufassen ist.

Die folgenden noch zu betrachtenden Schnitte sind in einer Ebene, quer zum Faserverlaufe des Nervus angelegt; sie treffen also, wie man sich leicht an der Hand der Fig. 3 vergegenwärtigen kann, die Chiasmagegend sehräg zum Faserverlaufo.

Sowie man in die hirtersten Chiasmaebenen (Fig. 5) eintritt, sieht man, wie sich an das markweisse Areal ein dichter, tiefrother Saum von Bindesubstarz anlegt, der am ventralen Rande entlang verläuft und lateralwärts immer dünner wird, so dass er nicht einmal bis zor Mitte des Gesammtquerschnittes reicht. Ausser diesem scharf begrenzten atrophischen Saume findet sich noch dorsal von demselben in der medialsten, spitz zulaufenden Partie des ungekreuzten Bündels eine geringe Menge mit Nervenfasern durchsetztes Bindegewebe.

In den vordersten Chiasmaebenen (Fig. 6) finden wir die atrophische Partie wiederum ventral von dem erhaltenen Nervenquersehnitte liegend; sie bildet hier mit ibrer Hauptmasse ein schmales, scharf begrenztes dreieckiges Feld, welches seine Basis gegen die Mittollinie kehrt und lateralwärts sich allmälig verjüngt, so dass es eben noch über die Halbirungslinie des Präparates hinausreicht; aber auch den ganzen medialen und $3 / 4$ rom dorsalen Rande desselben umgiesst es mit schmalem Saume und erstreckt sich hier in dünnen Bälkchen zwischen die nächsten Gruppen von Nervenfasern, welche hier zuerst sich in Bündeln zu formiren anfangen.

Es ist klar, dass das dreieckige Feld sammt dem schmalen Saume den Bindegewebsrest der beiden gekreuzten und des linken ungekrenzten Bündels vorstellt; in wieweit die Commissura inferior daran betheiligt ist, kann ich nicht entscheiden; doch liegt es am nächsten ihre Residuen in dem Saume am dorsalen Rande zu suchen, um so mehr, als dieser weiter vorne in Querschnitten, welche dem Nerven angehören, verschwunden ist. Solche Schnitte unterscheiden sich von der Fig. 5 nur dadurch, dass jener Saum fehlt und das dreieckige atrophische Feld an der ventralen Seite etwas kleiner geworden ist.

In einer mehrere Millimeter vor dem Chiasma gelegenen (mit Osmiumsäure behandelten) Partie (Fig. 7) bat der Nerv eine drehrunde Gestalt angenommen. Auch hier liegt der Rest des atrophirten gekreczten Bündels compact beisammen und bildet am Rande eine schmale Sichel, die nur an einem Ende zwischen die Nervenbündel eindringt und eine kleine Gruppe derselben von der Hauptmasse absprengt. Ich vermag aber nicht zu sagen, welches an diesem Präparate der mediale, und welches der laterale Rand ist. Die Grössendifferenz zwischen dem Nerven- (Fig. 7) und dem Tractusquerschnitte (Fig. 3) ist offenbar Folge der verschiedenen Härtungsmethoden. 
Abgesehen von dem Verlaufe der beiden Opticusbündel zu einander giebt Fig. 6 noch zu einigen Bemerkungen Veranlassung. In dem atrophischen Dreiecke findet sich nämlich eine schräg gestellte Spalte, welche von Epithel ausgekleidet, nach vorne sich noch durch eine Anzahl von Schnitten erstreckt, dann blind endigt, nach hinten aber alsbald mit dem III. Ventrikel communicirt. Sie ist ein Recessus des letzteren, von $\mathrm{Michel}^{*}$ ) bereits beim Menschen und versehiedenen Hausthieren beschrieben. Michel vindicirt derselben eine Bedeutung für das Zustandekommen hemiopischer und anderer Gesichtsfelddefecte in Folge hydropiseher Ansammlungen im III. Hirnventrikel; mit Rücksicht hierauf bemerke ich noch, dass der Recessus ganz von den atrophischen gekreuzten Bündein umschlossen wird, ein Verhältniss, welches - die Richtigkeit des Michel'schen Raisonnements vorausgesetzt — vielleicht für die Entstehung heteronymer temporaler Hemianopsie aus e in er. Ursache von Bedeutung sein könnte**).

Im Uebrigen bemerkt man roch in der Fig. 6, welche ziemlich genau dem Uebergangswinkel des Tractus zum Nervus entspricht, dass eine grosse Masse von Nervenfasern sich aus der lateral-ventralen in die medial-dorsale Partie des ungekreuzten Bündels begeben. Es resultirt daraus also eine derartige Verschiebung der Fasern des ungekreuzten Bündels gegen einander, dass diejenigen, welehe im Tractus am lateralen Rande verliefen, im Nerv den medialen Rand bilden und umgekehrt.

Meine bisherigen Untersuchungen, kurz zusammengefasst, ergeben dass bei der Katze die ungekreuzten Opticusfasern im Chiasma und Nerv als geschlossenes Bündel, entlang dem lateralen Rande beider verlaufen, so zwar, dass sie das gekreuzte Bündel an dessen dorsaler Seite noch ein wenig decken; zwischen beiden besteht höchstens eine verschwindend kleine Zone gemischter Fasern. Das ungekreuzte Bündel bildet somit bei der Katze einen wirklichen Fasciculus lateralis im Sinne von Hannover.

Dieses Resultat steht in schroffem Gegensatze zu der Kellermann'schen Darstellung von der Durchflechtung beider Bündel im Chiasma. Angesichts dessen muss ich entweder eine totale Verschiedenheit zwischen Katze und Mensch annehmen, oder ich muss versuchen, den Abbildungen von Kellermann eine andere Deutung zu geben, als er selbst ihnen hat angedeihen lassen.

Zunächst sei bemerkt, dass der Fall von Kellermann unrein ist; durch die partielle Atrophie des rechten Sehnerven neben der totalen des linken, gewinnt er für die anatomische Untersuchung ge-

*) Michel, Veber den Bau des Chiasma nervor. optic. in v. Graefe's Arch. f. Ophthalm. XIX. 2. p. $80 \mathrm{ff}$.

$\left.{ }^{* *}\right)$ Vgl. Ma nthner, Gehirn und Auge p. 416. 
wiss nicht an Klarheit, so interessant jene Complication der klinischen Betrachtung auch erscheinen mag. Aber mehr als dies: Kellermann nimmt an, dass „die aufsteigende Atrophie des linken Nervus eine absteigende Atrophie einer Gruppe des andern Nervus auf dem Wege durch das Chiasma herbeiführte", und zwar durch Compression in Folge eines Schrumpfungsprocesses der atrophischen Fasern vom linken Nervus. Dieser Process ist wohl wahrscheinlich ein progressiver von sehr langsamem Verlaufe gewesen, wenn er seit der Atrophie des linken Nervus (in 37 Jahren) sich nur auf eine kleine Gruppe des rechten Nervis erstrecken konnte.

Somit mag recht wohl der Degenerationsprocess im Chiasma eine viel grössere Ausdehnung erreicht haben, als sich aus der Atrophie beider Nerven erschliessen lässt. Wäre dies der Fall, so könnte von einer Verfolgung des gekreuzten resp. ungekreuzten Bündels durch das Chiasma hindurch keine Rede sein, und so scheint es sich in der That zu verhalten. Wenn ich die Fig. 5 von Kellermann betrachte und die Textbeschreibung dazu, so wird es mir mehr als wahrscheinlich, dass sich in seinem Falle die Chiasmaatrophie auch auf die Commissura inferior erstreckte. Kellermann sagt zwar (p. 38) „dass die Commissura arcuata posterior sich auch in diesem Falle ebenso präsentirte wie im ersten, nämlich als eine Gruppe von markbaltigen Nervenfaserbündeln, die längs des hinteren Chiasmawinkels und des medialen Randes des Tractus von einer Seite zur andern liefen, mit den Nervenfasern des Chiasma aber in. keinem näheren Zusammenhang standen“.

Mit diesen letzten Worten ist die Lage der Commissura inferior in nicht genügender Weise charakterisirt. Die ersten genaueren Angaben über ihre Lage im Tractus des Menschen. hat v. Gudden*) nach der Kellermann'schen Arbeit gegeben; aus seinen Untersuchungen geht hervor, dass die Commissura infer. beim Menschen sehr gross ist, und dass sie nicht am medialen Rande des Tractus verläuft. Ueber ihre Lage im Chiasma haben wir überhaupt keine genaue Kenntniss. Kellermann lässt sich weder anf eine Erörterung dieser Frage ein, noch giebt er eine genaue Erläuterung: seiner Fig. 5. - Dass er beides nicht that, rechne ich der Beschaffenheit seines Präparates zu Gute. Diese Fig. 5 ist ein „Durchschnitt durch das Chiasma nächst seinem hinteren Ende; sie musste mindestens im Mittelstücke, oder in den Seitenhälften Theile der Com-

*) In Graefe's Archiv f. Ophthalm. Bd. XXV. 4. Abbild. 3 u. 5. 
missura infer. enthalten; - wie mir scheint, enthält sie dieselbe in beiden. In dieser Auffassung werde ich bestärkt durch Präparate, welche mir Herr Dr. Bumm ans seiner Sammlung in dankenswerthester Weise zur Benutzung überlassen hat. Es sind Frontalschnitte durch ein mit 2 procentiger Osmiumsäure behandeltes Chiasma, welches von einem seit vier Jahren vollständig erblindeten Paralytiker stammte; die Totalatrophie beider Nervi optici wurde gleichfalls durch Osmiumsäure nachgewiesen. Diese Schnitte zeigen in einer Ebene, welche noch vor der Fig. 5 von Kellermann liegen muss, die Commissura inferior isolirt erhalten; als ein Band von $0,82 \mathrm{Mm}$. Dicke läuft sie quer durch das Mittelstück des Chiasma hindurch. Kellermann sagt nicht, ob die Commissura in seiner Fig. 5 enthalten ist, oder nicht; er scheint aber das Letztere anzunehmen. Nach dem Gesagten kann ich nicht zugeben, dass die Untersuchung von Kellermann Stichhaltiges gegen die Auffassung des ungekreuzten Bündels als eines Fasciculus lateralis beigebracht habe.

Geringer ist der Gegensatz, in welchen ich zu den Resultaten v. Gudden's treten muss; ergiebt sich ja auch aus diesen, dass beide Opticusbündel wenigstens im Tractus compacte, ziemlich gut geschiedene Faserzüge bilden; der Unterschied besteht darin, dass nach v. Gudden das ungekreuzte Bündel zuerst an den medialen Rand des gleichseitigen Nerven gelangt. Ich habe die bezüglichen Präparate von Herrn Professor v. Gudden untersucht, vermag aber den - keineswegs bedeutungslosen - Widerspruch in unseren Resultaten nicht zu heben.

Der Durchtritt des Nervus opticus durch den Canal der äusseren Augenhäute wird durch die Fig. 8 wiedergegeben. Man sieht hier sofort, dass das nasale Drittel von Nervenfasern vollständig frei ist, und das ungekreuzte Bündel ausschliesslich in den temporalen zwei Dritteln verläuft. In der nasalen nervenfreien Partie finde ich bei stärkerer Vergrösserung nur die Querbänder der Lamina cribrosa' ausserdem wie im ganzen Nerv zahlreiche ovale, fein granulirte Kerne, welche ich den die Nervenfasern umscheidenden endothelartigen Bindegewebszellen zuschreibe. Bemerkenswerth ist noch der Unterschied, welchen die seitlichen Conturen des Nerven beim Uebergange zur Papille zeigen. Während auf der nasalen Seite die Grenzlinie des Nerven fast in gerader Linie bis zum Rande der Papille verläuft, muss die temporale, um jenen Rand za erreichen, einen steilen Bogen beschreiben, und dies wiederholt sich im Verlaufe der einzelnen Nervenbündel. 
Die Papille selbst zeigt eine geringe Excavation, welche letatere bei den Katzen überhaupt individuell sehr verschieden ist. Sie bleibt in diesem Falle hinter der normalen Papillenbreite beträchtlich zu. rück; beispielsweise fand ich die letztere bei einer viel kleineren, und nicht ausgewachsenen Katze $0,95 \mathrm{Mm}$, und bei einer anderen mit der Katze A. gleich alten, aber central hemiopischen (Katze B.) 1,10 Mm. breit, während A. nur 0,70 Mm. im grössten Durchmesser aufwies, - alles in der horizontalen Quere gemessen.

Auch innerhalb der Papille nehmen die Nervenfasern ausschliesslich die temporalen 2 Drittel ein; sie bilden hier in der Mitte ein oberflächlich gelegenes, quergeschnittenes Bündel, welches sich vorzugsweise nach oben und unten hin vertheilt, während die grössere Masse der Fasern temporalwärts zieht; das nasale Drittel wird von fünf Gefässen und wenigen dieselben locker umhüllenden Bindegewebsfasern erfüllt; Nervenfasern liegen daselbst gar keine.

In der ganzen Netzhaut ist der Befund ein dem Verhalten der Papille analoger. Die Nervenfasern verbreiten sich ausschliesslich in der temporalen Hälfte, während in der nasalen eine auf die Nervenfaser- und Ganglienzellenschicht sich erstreckende vollständige Atrophie aller nervösen Theile eingetreten ist.

Vergleicht man beide Seiten bei schwacher Vergrösserung (Fig. 8) mit einander, so fällt zunächst der bedeutende Dickenunterschied auf, welcher in Bezug auf die innersten Lagen zwischen beiden Seiten besteht; es messen dieselben (Nervenfaser- und Ganglienzellenschichte) z. B. auf der temporalen Seite in einer Entfernung von $0,4 \mathrm{Mm}$. vom scharfen Rande der Papille 0,06 Mm., auf der nasalen dagegen nur 0,025 Mm.; das Verhältniss gestaltet sich noch mehr zu Ungunsten der letzteren Seite, wenn man näher an der Papille misst. Von weiteren Zahlenangaben nehme ich Umgang, indem ich das Verhalten durch die Fig. 8 für genügend illustrirt erachte.

Auch das Aussehen der zwei inneren Schichten ist auf beiden Seiten ein verschiedenes: nasal ein schmaler, heller, von Fasern gänzlich entblösster Saum, der eine weitere Schichtung nicht erkennen lässt, temporal dagegen, namentlich gegen die Peripherie zu, eine deutliche Scheidung der Ganglienzellen von den Fasern.

Die Figuren 9 und 10 geben bei stärkerer Vergrösserung das Aussehen beider Seiten wieder. Die erstere bedarf einer weiteren Erläuterung nicht, dagegen muss ich an Fig. 10 einige Bemerkungen knüpfen. Der lichte Saum, welchen ich für die atrophische Nervenfaser- und Ganglienzellenschichte erklärt habe, hat ein schwer zu 
zeichnendes, in der Abbildung übrigens recht gut wiedergegebenes Anssehen. Die Membrana limitans hyaloidea bildet hier keine scharfe Linie, sondern sie ist unregelmässig zackig; dies ist keineswegs durch eine Verletzung des Präparates bedingt, sondern dadurch, dass von den innersten Netzhautlagen nur die leere und collabirte Stützsubstanz erhalten ist. Zarte Linien, wie sie durch die Faltung glasheller, dünner Membranen entstehen, laufen unregelmässig quer durch den Saum und geben demselben ein Ansehen, als ob er aus dünnen mannichfach schalenartig gekrümmten Platten zusammengesetzt wäre; in der That bin ich der Ansicht, dass der ganze Saum nächst den Müller'schen Radialfasern und deren basalen Verzweigungen an geformten Elementen nur die glatten, endothelartigen Zellen enthält, welche Schwalbe*) aus den beiden innersten Netzhautlagen beschreibt. Für diesen Zellen und vielleicht noch den Müller'schen Radialfasern angehörig betrachte ich auch die Kerne, die in verschiedener Grösse in dem atrophischen Saume vorkommen.

Die Frage, ob sich die Atrophie des Nervus opticus auch auf die Ganglienzellenschichte der Netzhaut ausdehne, ist seit langer Zeit strittig. Sie wurde von Lehmann**) und v. Wahl***) verneint, dagegen von Krause $\dagger$ ), $\mathrm{Manz} \dagger$ ) und Berlin $\mathrm{K}_{\dagger} \dagger$ ) bejaht. In neuerer Zeit haben sich dann noch Kollmann*†) und Bumm** ${ }^{*}$ ) sowie auf deren Untersuchungen gestützt v. Gudden ${ }^{* * *} \dagger$ ) in verneinendem Sinne ausgesprochen. Kollmann untersuchte Netzhäute von Kanin-

*) Schwalbe im Handbuch der ges. Augenheilkunde, Bd. I. p. 378 and 384 .

**) Lehmann, Experimenta quaedam de nervi optici dissecti ad retinae texturam vi et effectu. Dissert. Dorpat 1857.

***) E. de Wahl, De retinae textura in monstro anencephalico disquisitiones microscopicae. Dissert. Dorpat 1859.

†) W. Krause, Die Membrana fenestrata der Retina. Leipzig 1868.

†) Manz, Das Auge der hirnlosen Missgeburten. Virchow's Archiv. Bd. 51.1870.

††† R. Berlin, Ueber Sehnerrendurchschneidung. Monatsbl. f. Augenheilk. IX. p. 278-305. 1871.

* ${ }^{+}$) Vgl. den Aufsatz v. Gudden's in v. Graefe's Arch. f. Ophthalm. XX. 2. p. 258.

†) Vortrag in der V. Wandervers. der Südwestdeutsch. Neurologen und Irrenärzte. Dieses Ȧrchiv Bd. XI. p. 265.

*** $\dagger$ ) In v. Graefe's Archiv f. Ophthalm. Bd. XXV. 1. p. 27 und ebenda Bd. XXV. 1. p. 238. 
chen, deren Sehnerven experimentell zur totalen Atrophie gebracht waren, Bumm eben solche und atrophische Netzhäute vom Menschen.

Dem gegenüber muss ich hervorheben, dass die Retina des Kaninchens viel reicher ist an bindegewebiger Stützsubstanz als die der Katze, was schon aus der Angabe von Bumm hervorgeht, das nasale Opticusbündel sei in der atrophischen Kaninchennetzhaut durch einen bindegewebigen Wulst von 0,033 Mm. ersetzt gewesen. Was dagegen bei der Katze schon am Nervus opticus anfgefallen ist, die geringe Menge des bei der Atrophie zurückgebliebenen Bindegewebes, das wiederholt sich in der Netzhaut: die bindegewebige Stützsubstanz der Nervenfaserschichte ist so gering, dass sie auf der atrophischen Seite nicht als eigene Lage angetroffen wird, sondern mit den Resten der Ganglienzellenschichte verschmilzt. Dieser Unterschied zwischen Kaninchen und Katze erklärt sich nur theilweise dadurch, dass bei ersterem die Nervenfasern in der Retina noch markhaltig, bei letzterer aber marklos sind, er geht durch alle Schichten durch, wie ich mich an. schönen Präparaten, deren Durchsicht Herr Dr. Bumm mir gütigst gestattete, überzeugt habe. Damit geht Hand in Hand, dass die Differencirung der nervösen Elemente bei der Katze viel weiter geht als beim Kaninchen, ja an sonst guten Normalpräparaten vom Menschen, die allerdings nicht ganz frisch zur Untersuchung gelangten, fand ich die Ganglienzellen viel weniger charakterisirt als bei der Katze.

Gegenüber den entgegenstehenden Angaben musste ich mich fragen, ob die Deutung, welche ich den Kernen der atrophischen Netzhautpartie oben gegeben habe, die richtige sei, und ob sie nicht ebensowohl als die. Kerne von Ganglienzellen aufgefasst werden könnten deren übrige Bestandtheile sich aus irgend einem Grunde der Beobachtung entzögen.

Ganglienzellen finde ich in der Katzenretina in der Grösse von 12-30 $\mu$ Durchmesser; mit Kernen von 6,4-11 $\mu$. Nun sind allerdings auch in der atrophischen Partie Kerne bis zu 6 , ja sogar bis zu $8 \mu$ Durchmesser vorhanden; die meisten sind einfach granulirt, doch besitzen auch manche ein Kernkörperchen. Dies berechtigt aber keineswegs, sie als Kerne yon Ganglienzellen aufzufassen, denn əinmal finde ich ganz die gleichen Elemente in der Nervenfaserschichte und in der Papille der normalen Retina, wo sie also ganz gewiss nicht als Bestandtheile von Ganglienzellen gelten können, sodann haben sie durchgehends ein etwas anderes Aussehen als die Kerne der letzteren: es fehlt ihnen die bläschenförmige, plastisch vortretende Gestalt und der Glanz des grossen Kernkörperchens, 
welche jene auszeichnen. Aber selbst angenommen, dass diese Kriterien im Stiche liessen, so ist für mich schon der Umstand entscheidend, dass ich auf der nasalen Seite in der ganzen Reihe kein einziges Element mit allen Attributen der Ganglienzelle finde, während auf der temporalen Seite derselben Präparate ganze Reihen der schönsten Exemplare schon bei schwacher Vergrösserung in die Angen fallen.

Es fragt sich nun, wie verhält sich die Area centralis in diesem Falle? Ich vermag eine sichere Antwort darauf nicht zu geben; zwar finde ich nirgendwo eine Anhäufung von Ganglienzellen, die ich als Area auffassen dürfte -- noch eine dem Ausfalle der letzteren entsprechende atrophische Stelle in der Zellenschichte; überall in der muthmasslichen Gegend der Area sehe ich eine einfache Lage von Ganglienzellen, die sogar bis auf $1,5 \mathrm{Mm}$. vom Rande der Papille eine continuirliche ist; vielleicht gehen diese Zellen noch näher an die Papille heran, sie werden ja stets im nächsten Umkreise derselben von der dicken Fasersehichte verdeckt und der Beobachtung entzogen. Somit existiren bei dieser Katze Ganglienzellen in dem Raume zwischen der Opticuspapille und der Area centralis, die ja um $1 \mathrm{Mm}$. weiter temporal liegt, Ganglienzellen, welche dem ungekreuzten Bündel zugehören. Es liegt nahe, auf diesen Befund hin anzunehmen, dass die Area centralis nicht vollständig atrophirt, sondern nur an Zellen verarmt sei, dass somit auch das ungekreuzte Bündel an der Faserverbindung derselben Antheil habe. Ich würde dies unbedenklich aussprechen, wenn in meiner Schnittreihe nicht hier und da bei der Präparation ein Schnitt ausgefallen wäre. Die Entscheidung in diesem Punkte bleibt somit einer erneuten Untersuchung vorbehalten.

Noch mit der Abfassung dieses Aufsatzes beschäftigt, erlangte ich bei der Section eines 72jährigen Epileptikers, der seit Jahren blödsinnig gewesen und im Status epilepticus zu Grunde gegangen war, ein sehr interessantes Präparat, dessen Verwerthung Herr Prof. v. Gudden mir zu gestatten die Frenndlichkeit hatte. Während des Lebens hatte der Fall zn genauer Untersuchung der Augen niemals Veranlassung gegeben; auf der rechten Cornea hatte der Kranke ein centrales, etwa $2 \mathrm{Mm}$. breites Leucom. Die Section des Gehirns hatte abgesehen rom Sehapparate ein negatives Ergebniss. Ich gebe in Fig. 11 eine naturgetreue, genau in situ angefertigte Abbildung vom Chiasma und den Tractus optici. 
Das ungekreuzte Bündel verläuft hier auf der rechten Seite eine lange Strecke vollständig isolirt, indem es wenig vor dem lateralen Kniehöcker sich von dem übrigen Tractus opticus loslöst und als dünnes Band, nur durch ein Blatt der weichen Hirnhaut mit jenem verbunden, ventral über den hinteren Rand desselben zieht, etwas hinter dem Chiasma einen Winkel bildet und direct sich an die laterale Seite des rechten Sehnerven begiebt; so verläuft es weiter, bis es $34 \mathrm{Mm}$. vom Bulbus entfernt in die Scheide desselben eintritt und makroskopisch nicht mehr von ihm zu trennen ist. Wenn ich, wie es nahe liegt, den grösseren rechten Nerv als das gekreuzte Bündel dieser Seite anspreche, so wird zunächst die relative Kleinheit des ungekreuzten Bündels auffallend erscheinen; Mauthner") erschliesst ans mancherlei Anhaltspunkten ein Verbältniss des gekreuzten zum ungelreuzten Bündel, wie $3: 2$; hier würde das Verhältniss scheinbar mehr zu Ungunsten des ungekreuzten ausfallen; allein die Zeichnung giebt von der relativen Stärke beider Bündel eine unrichtige Vorstellung, da das gekreuzte, wie der frische Querschnitt lehrte, eine sehr dicke, das ungekreuzte eine sehr dünne Scheide besitzt.

Vergleicht man die beiden dickeren Nerven mit einander, so ergiebt sich, dass nach dem Augenscheine beide gleich gross sind, ein Verhältniss, welches mich vermuthen lässt, dass das ungekreuzte Bündel links gar nicht zur Entwicklung gekommen ist, dass wir also auf dieser Seite bloss das gekreuzte Bündel vor uns hätten. Damit stimmt, dass der rechte vordere Hügel und dessen Arm etwas stärker zu sein scheinen als die entsprechenden Theile links. Abschnitte beider Nerven, sowie die Netzhäute sind mit Osmiumsäure behandelt worden und sollen namenlich auf das Verhalten der Macula lutea, welche in beiden Augen vorhanden war, genaner untersucht werden.

Darin liegt nach meiner Meinung der Schwerpunkt des Interesses, welches das Präparat beanspruchen darf; hier habe ich dasselbe nur deshalb mitgetheilt, weil es das erste seiner Art ist, welches zur literarischen Kenntniss ${ }^{* *}$ ) gelangt. Als Beweismaterial für das Lageverhältniss beider Opticusbündel möchte ich dasselbe nicht heranziehen, da man in dieser Beziehung stets den Einwand erheben könnte, dass es bloss den Werth einer Varietät besitze.

Herr Prof. v. Gudd en***) hat im Jahre 1875 eine kurze Beschreibung eines Hundehirns gegeben, bei welchem in Folge einer bald nach der Geburt vorgenommenen Exstirpation eines Theils vom Hinterhauptshirne eine beträchtliche Atrophie des gleichseitigen Tractus

*) Gehirn und Auge p. 427.

**) Vgl. die Zusammenstellung der literarisch bekannten Fälle von ungekreuztem Verlaufe des Nervus opticus bis zum Bulbus bei Henle, Handb. der Nervenlehre des Menschen 1871 p. 348 und bei v. Gudden in Graefe's Archiv f. Ophthalm. XXV. 1. p. 37.

$\left.{ }^{* * *}\right)$ v. Graefe's Archiv f. Ophthalm. XXI. 3. p. 202. 
opticus eingetreten war. Diese wie die gleichzeitig vorgefundene Atrophie des einen Gesichtssinnscentrums erklärte v. Gudden als ausser directem Zusammenhange mit der Operation stehend, vielmehr entstanden durch den Druck, welchen die hydropische Ansammlung von dem eröfineten Seitenventrikel aus auf den vorderen $Z$ weihügel ausgeübt habe. Die Frage, wie diese Atrophie zu Stande gekommen ist, bietet nach verschiedener Richtung hin grosses Interesse; wäre sie z. B. keine einfache Druckatrophie, sondern eine directe Fortsetzung eines degenerativen Processes, der sich zuerst in der Hirnrinde etablirt hat, so wäre es vielleicht möglich, mittelst des Augenspiegels intra vitam wichtige diagnostische Aufschlüsse zu erlangen, auch in Fällen, bei welchen erhebliche Druckmomente nicht wirksam sind.

Mich hat die Erklärung v. Gudden's, wie ich gleich gestehen will, nicht ganz befriedigt, zum Theil aus allgemeinen später zu erörternden anatomischen und physiologischen Erwägungen. Ich habe deshaib den Versuch 2 mal wiederholt, jedesmal in anderer Weise, und gebe als Beitrag zur exacten Lösung der schwebenden Frage hier meine Resultate.

Als Versucbsthiere habe ich anch in diesem Falle aus den früher erwähnten Gründen neugeborene Katzen gewählt; meine anfänglichen Bedenken in Bezug auf ihre Lebensfähigkeit nach schweren centralen Eingriffen haben dieselben glänzend widerlegt.

\section{Vorsuch.}

Der Katze B. habe ich, als sie zwei Tage alt geworden war, nach einem durch die Haut geführten Sagittalschnitte die Schädellapsel geöffnet *), indem ich die linke Lambda- und Coronarnaht, von der Mittellinie ausgehend, trennte und in der grössten Circumferenz des Schädels durch einen Schnitt durch der Knochen verband; das Schädelbein, an drei Seiten frei gemacht, wurde um die Sagittalnaht aufgellappt, die harte Hirnhaut zurückgeschoben und mittelst eines scharfen Löffelchens ein vorher mit dem Messer umgrenztes Stück der Grosshirnrinde der linken Occipitalgegend entfernt; der Griff ging so tief, dass ich das Ammonshorn frei vorliegen sah; es war snmit der Seitenventrikel eröffnet. Nachdem das Scheitelbein wieder zugeklappt war, wurde die Hant vernäht.

Das Thierchen entwickelte sich in ganz normaler Weise, verliess zur gewöhnlichen Zeit das Lager und zeigte ron Anfang an bei der gewöhnlichen Beobachtung nicht die geringste Abnormität, weder in

*) Diese Art zu experimentiren, ist durch v. Gudden in seinen experimẹntellẹ Untersichungen an mehreren Steller beschrieben. 
der motorischen noch in der sensitiven Sphäre. Es orientirte sieh rasch, auch in fremdem Raume, vermied geschickt die Hindernisse, man mochte sie noch so zahlreich aufstellen, und nur der etwas stärkere Gebrauch der tastenden und schnüffelnden Schnauze konnte einem aufmerksamen Beobachter auffallen; doch unterschied sie sich darin nicht sehr von normalen ganz jungen Katzen, verlor dies auch vollständig in kurzer Zeit. Sie trug den Kopf, wie andere Katzen und schaute den gegenüber sitzenden Beobachter gerade an. Weder in den kleineren graciösen Bewegungen, welche die Katzen bei ihrem Spiele ausführen, noch in den ausgiebigen, rasch aufeinanderfolgenden Sprüngen und Schlägen beim Ringen mit ihren Altersgenossen, war irgend etwas zu bemerken, was einen Defect im Gebiete des Gesichtssinnes angezeigt hätte; sie war treffsicher. Uebrigens war das Thier intelligent und besass die ganze List im Erlangen und die Behendigkeit im Bergen einer Beute, welche die Katzen auszeichnen.

Gleichwohl hatte dieses Thier einen grossen Defect im Gesichtssinne. Als ich eines Tages einen weissen Papierball geräuschlos an schwarzem Faden um das Thier herumschwingen liess, so dass derselbe im umgekehrten Sinne eines Uhrzeigers*) einen Kreis um dasselbe beschrieb, verlor es denselben keinen Augenblick aus den Augen, jagte demselben nach und erhaschte ihn sehr hänfig im Sprunge. In demselben Momente aber, wo ich den Ball umkehren, also im Sinne eines Uhrzeigers schwingen liess, blieb das Thier wie festgebannt sitzen, drehte in unsicherer Weise den Kopf nach allen Seiten, suchte den Ball, den es offenbar nur auf kurze Momente zu sehen bekam, war aber ganz ausser Stande, denselben in seiner Bahn zu verfolgen; niemals machte es einen Versuch den Ball zu haschen, auch wenn er in relativ langsamer Bewegung war. Der Unterschied im Verhalten des Thieres war im höchsten Grade auffallend. Er blieb der gleiche auch wenn das Thier ausserhalb des rom Ball beschriebenen Kreises sich befand, der gleiche, wenn ich ihm, gleichviel welches Auge mit einer um den Kopf gebundenen schwarzen Haube verdeckte: stets folgte es auf's genaueste dem negativ schwingenden Balle, und war über den positiv schwingenden gänzlich desorientirt. In anderer Weise mit den einzelnen Augen separirt angestellte Sehprüfungen ergaben nun, dass das Thier Gegenstände, deren Bild auf den temporalen Theil der linken oder solche, deren Bild auf den nasalen der rechten Netzhaut fiel, nicht sah und damit war die Bestätigung ge-

*) Ich will der Kürze halber die Richtung, in welcher sich der Uhrzeiger bewegt, die positive nennen, die entgegengesetzte die negative. 
geben für die Ansicht, welche mir schon der erste eclatante Versuch aufgedrängt hatte, dass die Katze nämlich an homonymer rechtsseitiger Hemianopsie beider Augen litt.

Es ist nicht so ganz leicht für das eigenthümliche Verhalten der Katze gegenüber meinem Versuche eine befriedigende Erklärung zu geben. Zuerst glaubte ich den Grund einfach darin suchen zu müssen, dass das Thier wegen der bedeutenden Einschränkung seines Gesichtsfeldes von rechts her die Umdrehung nach rechts, gleichsam als einen Sprung in's Dunkle vermeide und zwar um so mehr, als auch die ansgiebigste Drehung der Augen nach dieser Richtung hin das Gesichtsfeld nicht um die Länge eines Sprunges erweitert hätte. Wäre diese Erklärnng richtig, so hätte man erwarten müssen, dass die Katze die Linksdrehung gegenüber der Rechtsdrehung überhaupt bevorzuge und bei raschen Bewegungen ansschliesslich wähle; aber nichts von dem habe ich constatiren können: ich habe sie unzählige Male bei den Spielen mit anderen Katzen mit rascher Wendung nach rechts springen sehen, und wenn ich den Papierball auf dem Boden schleifend einen Kreis um sie herum beschreiben liess, so war in dem Verhalten nicht der mindeste Unterschied zu sehen, ob er nun in positiver oder negativer Richtung schleifte.

Ich habe deshalb von dieser Erklärung abgesehen und eine Zeit lang angenommen, dass das Thier allmälig durch die Erfahrung gelernt habe, die Gegenstände, deren Bilder überhaupt auf seiner Netzhaut zur Perception gelangten, in der links von der verlängerten Längsaxe seines Kopfes gelegenen Gegend zu suchen; bei der negativen Bewegung des Papierballs würde die erste Drehung der Augen, welche das Thier instinctiv gemacht hätte, sobald es derselben ansichtig wurde, mit der Bewegung des Balls übereingestimmt und somit dessen Verweilen im Gesichtsfelde verlängert haben, während bei der positiven Bewegung des Balls gerade das Umgekehrte hätte stattfinden müssen. Aber die Voraussetzung meiner Annahme, dass nämlich die erste Drehbewegung der Augen immer und unter allen Umständen meines Experimentes nach links gerichtet sei, konnte ich nicht als gegeben nachweisen. Auch wäre es auffallend gewesen, dass die Thiere geradeaus zu schauen pflegten, anstatt, wie es jener Annahme entsprochen hätte, ihre Augen und nöthigenfalls den ganzen Kopf habituell nach rechts zu drehen; auch dies hätten sie ja lernen können. Wäre endlich mein zweiter Erklärungsversuch richtig gewesen; so hätte es allmälig gelingen müssen, das Thier zu lehren, dass es sich mit gleicher Gewandtheit in positiver Richtung bewegte, wie in negativer. Meine darauf abzielenden Bemühungen waren in- 
dessen fruchtlose; und so habe ich mich denn auch von der Unrichtigkeit dieser Erklärtng überzeugt, und gebe hier eine andere, welche alle Einzelnheiten in dem Verhalten der Katze verständlich macht.

Ich nehme an, dass bei der Katze B. der Fixationspunkt noch innerhalb des erhaltenen Theiles des Gesichtsfeldes lag. Dies erklärt nicht nur die gerade Haltung des Kopfes, sondern ganz besonders die Fähigkeit und Gewohnheit des Thieres, mit conjugirten Blicklinien zu schanen, binocnlar zu fixiren. Setzt sich nun bei dieser Stellung der Augen der Papierball in negativer Richtung in Bewegung, so wird er, selbst wenn die Augen nur ganz langsam folgen, noch eine Weile im perjpheren Gesichtsfelde sein, während er in Folge der geringsten Bewegung in positiver Richtung vollständig aus dem Gesichtsfelde verschwunden ist und zwar um so rascher, je näher die Grenze des Gesichtsfeldes am Fixationspunkte gelegen ist.

Diese Erklärung trifft für das binoculare wie für das monoculare Sehen za; sie macht es auch verständlich, dass meine Bestrebungen, das Thier in der Bewegung nach rechts zu unterrichten, fruchtlos waren.

Die Katze B. wurde 9 Monate alt und war vollständig ausgewachsen. Herr Dr. Eversbusch hatte auch in diesem Falle die Freundlichkeit die ophthalmoskopische Untersuchung vorzunehmen und mir folgenden Befund zur Verfügung zu stellen:

Linkes Auge, aufrechtes Bild: Auch hier die bei der Katze A. und C. (s. unten p. 369) erwähnte netzförmige Zeichnung der Papille auf den ersten Blick erkennbar. Der Grad der Verbreiterung der einzelnen netzförmigen Bündel hält ungefähr die Mitte der bei $A$. und C. beobachteten. Die Ausdehnung der graulich weiss aussehenden Partie erstreckt sich bis in die Nähe des Centrums der Papille, so dass 2 Fünftel derselben pathologisch verändert erscheinen, die medial gelegenen 3 Fünftel aber das normale Aussehen haben. Zwei am Rande der Papille nach aussen ziehende Arterien, welche in diesem Bezirke gelegen sind, sind leicht verdünnt.

Auf dem rechten A uge ist die netzförmige Zeichnung der Papille fast noch deutlicher ausgesprochen als links; sie nimmt hier nicht allein die mediale Hälfte des Sehnervenquerschnittes ein, sondern erstreckt sich auch noch über die äussere Hälfte der Art, dass nur etwas mehr denn 1 Fünftel von normalem Aussehen ist. Ein auffälliger Untersehied in den Arterien ist hier nicht zu gewahren, da sie sich sämmtlich in den veränderten Partien verzweigen, jedoch sind sie entschieden gegenüber den in den normalen Partien der linken Papille verlaufenden verschmälert.

Tod durch Chloroform. Bei der Herausnahme des Gehirns erschien die barte Hirnbaut in der Umgebung des operativen Defectes mit den weichen Häuten verwachsen: beim Anschnẹiden derselben erhielt manEinblicke in den lin- 
ken Seitenventrikel, welcher mit klarer Flüssigkeit nicht ïbermässig angefüllt war.

Der Befund am Gehirne selbst wird durch die Fig. 12 und 13 wiedergegeben.

Die linke Grosshirnhemisphäre schien in toto, namentlich aber in ihrem hinteren Theile verkleinert; der hintere Rand lag 2,5 Mm. weiter nach vorne als rechts und der Unterschied in der Breite war noch grösser: er betrug an einer Stelle $9 \mathrm{Mm}$. zu Ungunsten der linken Seite. Es fand sich ein von scharfen Rändern begrenzter, unregelmässig runder Defect in der Hirnrinde, welcher grösstentheils im Bereiche des medialen Gyrus lag, in dieser Richting über die Fissura lateralis hinaus, nach aussen fast bis zur Fissura suprasylvia posterior ( $\mathrm{Krueg}$ ) reichte; die benachbarten Furchen liefen radienförmig gegen den Defect zusammen, innerhalb dessen das Ammonshorn frei zu Tage lag.

An der Basis zeigte sich der linke Tractus opticus deutlich verkleinert und zwar sowohl in der Breite — so dass die Commissur von Meynert hier schöner zu Tage tritt als rechts - als auch in der Dicke, er ist flacher als der rechte Tractus. An den beiden Sennerven ist dieser Unterschied ziemlich verwiseht für die makroskopische Betrachtung; man bemerkt, dass der Winkel, welchen rechter Sehnerv und Tractus mit einander bilden, von einem, auf der linken Seite fehlenden Walste umzogen ist, der, wie oin Vergleich mit Fig. 1 und mit Präparaten von einseitig peripher geblendeten Katzen mir beweist, auf die Integrität des rechten ungekreuzten Bündels zurückzuführen ist. Der Tractus peduncularis transversus ist auf beiden Seiten erhalten. Der linke vordere Zweihügel ist nach Breite und Länge kleiner als der rechte, die medialen Kniehöcker beiderseits gleich, die lateralen für die Untersuchung unzugänglich.

Die mikroskopische Untersuchung erstreckte sich auf die Nerven und die Retina. Von den ersteren wurden Abschnitte mit 2 procentiger Ueberosmiumsäure behandelt, in Alkohol vollends gehärtet und mit dem Mikrotom in möglichst exact querer Richtung geschnitten. Dio Fig. 14 giebt bei 23 facher Vergrösserung, welche mittels derCamera obscura hergestellt wurde, die Conturen beider; der kleinere ist der rechte.

In den Querschnitten fand sich nirgends eine Anhäufung von Bindesub$\operatorname{stanz}$, welche als Effect einer umschriebenen Atrophio hätto aufgefasst werden könrien.

Die an der Netzhaut gewonnenen Untersuchungsresultate gebe ich zugleich mit jenen, die an der nun zu beschreibenden Katze C. gewonnen wurden.

\section{Versuch.}

Am dritten Tage nach der Geburt warde der Katze C. in derselben Weise, wie ich's oben angegeben habe, die Schädelkapsel geöfnet, nur mit dem Unterschiede, dass der Knochenschnitt nach vorne nicht in der Coronarnaht endete, sondern bogenförmig duroh das Știrnbeịn bis zur Sagittalnaht 
geführt wurde, so dass, nachdem die in der Peripherie losgelösten Theile des Scheitel- und Stirnbeins um die Sagittalnaht umgeklappt waren, die linke Grosshirnhemisphäre grösstentheils zu Tage lag. Nachdem auch die harte Hirnhaut peripher getrennt und zurückgeschlagen war, ging ich mit einem Daviel'schen Löffel von hinten her, mich mehr an die Seitenwand des Schädels haltend, unter den Rand der Hemisphäre, hob dieselbe, so dass sie auf den Knochenrand zu liegen kam und trug, nachdem ich zuvor Balken und Fornix mit einem feinen Skalpell sagittal durchtrennt hatte, von der Mittellinie herkommend soviel von der Hemisphäre ab, als frei zu Tage lag, wobei ich mich des scharfen Löffels bediente und Sorge trug, dass die Stammganglien von jeder Verletzung verschont blieben. Die Blutung ist zwar stark, doch gelingt es, die Theile gut zu erkennen, namentlich wenn man rasch operirt; dies ist auch die beste Art, das Thier vor Verblutung zu schützen, wobei der Vortheil, den v. Gudden hervorgehoben hat, die starke Gerinnungsfähigkeit des Blutes der jungen Thiere sehr zu Statten kommt. Mit der Entfernung des Gerinnsels befasse man sich nicht; der Schädel wird wieder zugeklappt; der Hautschnitt sorgfältig durcli Nähto verschlossen.

Die Katze war einige Tage recht schwach, was ich fast ausschliesslich dem grossen Blntverluste zuschrieb, doch behielt sie Kräfte genug zum Saugen und erholte sich in Folge dessen bald. Als sie das Lager verliess, was beträchtlich später geschah, als bei normalen Kätzchen, konnte ich an ihren Gehversuchen keine Störung der Motilität beobachten; alsbald bewegte sie sich sehr gewandt, war sehr lebhaft und übernahm im Spiele mit ibren Altersgenossen stets die Rolle des Angreifers, gewann auch meist in Folge ihres Muthes und ihrer Sicherheit im Sprunge, wie in allen Bewegungen die Oberhand. Jener Altersgenosse war, beiläufig bemerkt, gleichfalls nicht normal, sondern hatte eine Exstirpation am linken Stirnhirne überstanden. Tn einem Punkte aber war die Katze C. dem letzteren von Anfang an und Zeit Lebens unterlegen, das war im Sprunge in die Höhe; erst gegen Ende ihres 3. Monates gelang es ihr nach manchen fruchtlosen Versuchen, Stuhl und Tisch zu ersteigen; allmälig vervollkommnete sie sich auch darin bis zu einem gewissen Grade. Noch eine andere anffällige Erscheinung bot sie dar: sie konnte nämlich nicht miauen; sie gab überhaupt sehr selten und nur bei starken äusseren Reizen einen Laut von sich, der aber mit dem Rufe der Katzen nichts gemein hatte, sondern ein ganz fremdartiges krächzendes Schnurren war. Prüfungen der Sensibilität ergaben, dass die Reflexerregbarkeit von der Conjunctiva bulbi und von der Haut aus überall gut erhalhalten war; besonders gut liess sich dies an den Haaren der Ohrspitzen constatiren, die bei der leisesten Berührung mit raschen Bewegungen der Ohrmuschel reagirten; dagegen schien am ganzen 
Körper die Schmerzempfindlichkeit bedeutend herabgesetzt: es bedurfte starker Püffe oder ordentlicher Nadelstiche, um das Behagen des Thieres zu stören. Uebrigens war die Katze psychisch schwach und dies wurde, je mehr sie erwuchs, immer klarer; während sie früher viel besser angelegt schien, als ihr Spielgenosse, wurde sie nun stündlich von diesem überfïgelt, der ihr jede Maus, welche die Mutter vom Felde hineintrug, wegschnappte. Sie war ohne Temperament, schwachsinnig zutraulich, hatte ein höchst mangelhaftes Gedächtniss und noch weniger Ueberlegung: wenn man sie z. B. am Schweife aufhob und frei in der Luft schweben liess - eine für die Katze keineswegs angenehme Procedur - so fiel es ihr, wenn sie wieder zu Boden gekommen war, nicht ein, davon zu laufen, sondern man konnte die gleiche Behandlung beliebig oft wiederholen.

In Bezug auf den Gesichtssinn verhielt sie sich ganz genau, wie die Katze B., so dass ich einfach auf das dort Gesagte verweisen kann; insbesondere gelang das Experiment mit dem Papierball vortrefflich; auch Haltung des Kopfes und Stellung der Augen wie bei B.

Die ophthalmoskopische Untersuchung durch Herrn Dr. Eversbusch ergab folgenden Befund:

Aufrechtes Bild: Der naheza rundlich configurirte Sehnerv links in seinen inneren 2 Dritteln von grauröthlicher Färbung mit schwacher Andeutung des Maschenwerkes der Lamina cribrosa in dieser Partie; dieses letztere tritt im temporalen Drittel des Sebnerveneintrittes auffällig deutlicher hervor, dabei sind die Züge erheblich verbreitert; eine genaue Abgrenzung dieser so veränderten Partie gegen den erst erwähnten medialen Abschnitt ist nicht vorhanden, vielmehr gehen die verbreiterten Bündel der Lamina cribrosa, sich allmälig verjüngend in die des inneren Papillarabschnittes über. Eine in dem temporalen Abschnitte nach unten und aussen verlaufende Arterie ist in ihrem Caliber gegenüber den arteriellen Verzweigungen, die an der übrigen Papillarperipherie verlaufen, etwa um ${ }^{1 / 3}$ des Normalcalibers verschmälert. Die sie begleitende Vene dagegen nicht.

Im Gegensatze zu dem grauröthlichen Farbentone der medialen, normal aussehenden Papillartheile sieht der temporale Papillarabschnitt grauweisslich aus; durch das stärkere Hervortreten der Maschen der Lamina cribrosa gewinnt dieser Theil eine netzförmige Zeichnung.

Auf dem rechten Auge tritt mit gleicher Deutlichkeit wie links die weissliche Verfärbung und netzförmige Zeichnung in den medialen Abschnitten der Papille hervor, jedoch ist die Ausdehnung des so veränderten Sehnervenabschnittes entschieden etwas grösser als links; sie nimmt ungefähr 2 Drittel des Gesammtareals ein; die Abgrenzung beider Partien von einander ist ebenso wenig scharf wie links.

Auch hier ist an einer nach oben und innen ziehenden Arterie eine Reduction des Calibers nicht zu verkennen, jedoch bei Weitem weniger ausge- 
sprochen als links. Im Uebrigen Aussehen und Configuration der rechten Papille ganz wie links.

C. wurde 6 Monate alt, durch Chloroform getödtet.

Bei der Section fand sich, dass von der linken Grosshirnhemisphäre nur erhalten war: der Bulbus und Lobus olfactorius nebst der Spitze des Schläfelappens, die Windung vor der Fissura cruciata, sowie dorsal von der Fissura rhinalis und rhinalis posterior ein Saum von $1 \mathrm{Ctm}$. Breite, der die Aussenfläche des Streifenhügels bekleidete.

Eine grosse Lücke, die mit Serum gefüllt und von der Dura mater überspannt gewesen war, gewährte über alle Gebilde des linken Seitenventrikels freien Ueberblick. Zwischen Streifen- und Sehhügel fand sich eine tiefe Spalte, entstanden durch die Atrophie der innern Kapsel; diese Atrophie hatte sich in ganz bedentendem Masse anch anf den Sehhügel und die beiden Kniehöcker erstreckt; namentlich der laterale war in seiner Gestalt verändert, zipfelförmig und nach hinten gedrängt, wie ich annohme, in Folge der eigeren Atrophie und der des Sehhügels; der linke vordere Zweihügel war in der Breite wie in der Länge beträchtlich kleiner als der rechte, dagegen stärker gewölbt.

Die rechte Hemisphäre völlig unverletzt war über die Mittellinie hinüber gerüclit; von der Fimbria des rechten Ammonshornes ging ein Faserzug (Fornixsäule) nach vorne gegen die Commissura anterior und schickte, bevor er sich hier ganz in die Tiefe senkte, ein kleines Bündel nach links zum Stratum zonale thalami optici* ${ }^{*}$.

Von der Basis betrachtet erscheinen beide Tractus optici auffallend schmal und dünn im Vergleiche mit dem Tractus der gleichalterigen mehrerwähnten Katze desselben Wurfes, doch ist zweifellos wieder der linke Tractus opticus schmaler und dünner, als der rechte; die Differenz ist relativ nicht so gross, wie sie bei der Katze B. gefunden wurde; immerhin gross genug, um auch noch an den beiden Nerven gloich nach ihrem Abgange erkennbar zu sein: der rechte Nerv ist etwas platter und dünner als der linke. Im Corpus mammillare ist das linke mediale Ganglion hochgradig atrophirt; der linke Pes pedunculi verschmälert, der vordere Rand der Brücke links abgeflacht, die liske Pyramide fast ganz geschwunden. Der Tractus peduncularis transversus ist beiderseits erhalten.

Die mikroskopische Untersuchung von Nervenabschnitten, die mit Ueberosmiumsäure ( 2 pCt.) behandelt waren, hat ergeben, dass die Bindegewebssepta, welche die Bündel der Fasern umscheiden, im Vergleich zu allen anderen bei dieser Gelegenheit untersuchten Sehnerven der Katze stärker entwickelt waren. Es kommen in dieser Beziehung sowohl bei niederen als höheren Säugern, auch beim Menschen grosse individuelle Verschiedenheiten vor; indessen im vorliegenden Falle gewinnt der Befund ein eigenes Ansehen im Zusammenhalte mit der auffallenden Kleinheit beider Tractus. Es wäre

*) Dies ist das „obere gekrenzte Bündel der Fornixsäule“ v. Gudden's (vgl. dieses Archiv XI. 2. p. 20. 
möglich, dass dieselbe Ursache, welche diese in der Entwicklung beschränkte, dadurch zngleich ein stärkeres Hervortreten der Bindesubstanz in den Nerven bedingt hätte; entscheiden lässt sich dies, denke ich, nicht.

Querschnitte beider Nerven 23 mal mit der Camera obscura vergrössert (Fig. 15) ergeben, das der linke Nerv grösser ist, als der rechte. Um zu veranschaulichen, in welchem Grössenverhältnisse beide Nerven zum normalen Opticus stehen, habe ich ihre Umrisse in die 23 fach vergrösserte Contur eines auf ganz gleiche Weiso präparirten Querschnittes rom normalen, gleichalterigen Opticus hineingezeichnet.

Es fand sich demnach, um dies kurz zu resumiren, bei beiden Katzen B. und C., dass die Atrophie, welche der mit der Hemisphärenexstirpation gleichseitige (linke) Tractus erlitten hatte, sich in ungleicher Weise auf die beiden Nerven und zwar mehr auf den entgegengesetzten (rechten) erstreckt hatte. Daraus folgt, - die Partialkreuzung als bewiesen vorausgesetzt - , dass das ungekreuzte Bündel bei der Katze kleiner ist, als das gekreuzte.

In den Netzhäuten beider Katzen B. und C. waren alle Schichten erhalten; nirgends vermochte ich eine umschriebene Atrophie nachzuweisen; die Area centralis fand ich deutlich ausgebildet in allen vier Retinae wieder, doch wage ich über den Gehalt an Ganglienzellen - ob normal oder rareficirt - kein Urtheil abzugeben.

Bei beiden Katzen fanden sich in je zwei Augen Differenzen in der Dicke der Nervenfaserschichte und zwar von homonym gleichwerthigem Charakter: bei beiden waren die linken Hälften beider Retinae mit einer dünneren Faserschichte versehen, als die rechten. Dieser Unterschied war besonders deutlich in der Papille, wo man am nasalen und temporalen Rande gute Anhaltspunkte für die Messung hat.

Während nach Untersuchungen, welche ich an einer normalen Katzenretina angestellt habe, die Faserschichte am nasalen Rande mindestens gleich dick mit der temporalen ist, fand ich hier in beiden Fällen durchgehends, dass in der linken Netzhant das nasale, in der rechten das temporale Bündel stärker war - also eine homonyme linksseitige Atrophie, entsprechend der rechtsseitigen homonymen Hemianopsie. Es verhielten sich z. B. bei der Katze B. die beiden Bündel ( $\mathrm{n}=$ nasal, $\mathrm{t}=$ temporal):

links

$$
\mathrm{n}: \mathrm{t}=0,090: 0,075
$$$$
\mathrm{n}: \mathrm{t}=0,120: 0,099
$$

rechts

$$
\mathrm{n}: \mathrm{t}=0,048: 0,060 \text { oder }
$$$$
\mathrm{n}: \mathrm{t}=0,033: 0,045 \text {; }
$$ 
bei der Katze $\mathrm{C}$.
links
rechts
$\mathrm{n}: \mathrm{t}=0,090: 0,072$
$\mathrm{n}: \mathrm{t}=0,135: 0,150$ oder
$\mathrm{n}: \mathrm{t}=0,075: 0,060$
$\mathrm{n}: \mathrm{t}=0,105: 0,120$.

Ein Punkt verdient hieraus noch hervorgehoben zu werden, das ist die Möglichkeit, die Atrophie im temporalen Bündel der der $\mathrm{He}$ misphärenexstirpation entgegengesetzten (rechten) Netzhaut nachzuweisen. Es durfte dies a priori nicht erwartet werden, wie aus folgender Erwägung hervorgeht.

Da nach der allgemeinen wohlbegründeten Annahme das gekreuzte Opticusbündel sowohl temporal- als nasalwärts sich verbreitet, so wird sich eine gleichmässig vertheilte Atrophie gleichfalls auf beide Seiten erstrecken, und zwar stärker auf die nasale als auf die temporale, da ja erstere ausschliesslich, wie ich exact bewiesen habe, vom gekreuzten Bündel versehen wird; es könnte also sehr wohl eine vorhandene Atrophie des temporalen Bündels unbemerkt bleiben; dass ihr Nachweis gelingt, macht es für mich wahrscheinlich, dass der temporale Theil des gekrenzten Bündels ziemlich bedeutend ist.

Meine Versuche an den Katzen B. und C. haben im Wesentlichen das gleiche Resultat gehabt, wie es bei.dem Hunde v. Gudden's zu Tage trat. Leider hat auch in meinen Fällen eine seröse Flüssigkeitsansammlung im Seitenventrikel stattgefunden, und so sehe ich mich bei der Beschaffenheit des vorliegenden Untersuchungsmaterials ausser Stande, die Frage nach der Ursache der Tractusatrophie in den drei beschriebenen Fällen zu einer endgültigen Entscheidung zu bringen. Das Material ist deswegen nicht werthlos und es verlohnt sich, einige Reflexionen daran zu knüpfen.

Dass Druckveränderungen innerhalb der Schädelhöhle ron grosser Bedentung für die Entwicklung des Gehirnes sind, ist unzweifelhaft. $Z_{\text {weierlei }}$ muss man hier unterscheiden, einmal die Verschiebungsund Ausgleichsphänomene, dann die Druckatrophien. Die ersteren treten unter gewissen Umständen regelmässig auf; Herr Professor v. Gudden hat an den verschiedensten Stellen seiner experimentellen Untersuchungen dieselben hervorgehoben, und ich habe oft Gelegenheit gehabt, sie an seinen Präparaten zu beobachten. Das Gehirn entwickelt sich am stärksten nach der Richtung des geringsten Druckes; wird der Druck einseitig vermindert, so rücken stets die erhaltenen Theile bis zu einem gewissen Grade in die entstandene Lücke ein; nach Exstirpation einer Hemisphäre schiebt die erhaltene über die Mittellinie vor, während gleichzeitig die dem Defect benachbarte 
Schädelpartie in der Regel etwas kleiner bleibt, als sie unter normalen Verhältnissen geworden wäre, immer aber sich verdickt. Soweit diese Vorgänge nicht ausreichen, die entstandene Lücke auszufüllen, geschieht dies durch Ansammlung seröser Flüssigkeit; die letztere tritt immer ein, wenn bei ausgedehnter Exstirpation der Seitenventrikel geöffnet wird. Diese Flüssigkeit übt offenbar keinen Druck aus, der zu einer Atrophie führen kann, die feinsten Faserzüge erhalten sich isolirt darin - ich denke hier namentlich an das obere gekreuzte Bündel der Fornixsäule und an das ungekreuzte Opticusbündel, beides beim Kaninchen Faserzüge von weniger als eines halben Millimeters Dicke.

Anders dagegen liegen die Verhältnisse, wenn an den operativen Eingriff sich ein entzündlicher Vorgang anschliesst, der die Tendenz zu progressiver Drucksteigerung mit sich bringt. An solehe Vorgänge wird man denken müssen in den Fällen, in welchen unter anderweitigen unzweifelhaften Erscheinungen erhöhten intracraniellen Druckes (z. B. Abscessbildung oder bedeutender Hydrocephalus internus) eine Atrophie gefunden wird, welche ohne jene Begleiterscheinungen nie getroffen wird. Solche Fälle sind beim Kaninchen ausserordentlich selten, aber sie kommen vor. Nun ist aber weder an dem Hunde v. Gudden's noch an meinen beiden Katzen etwas gefunden worden, was zur Annahme eines derartigen entzündlichen Vorganges nöthigt und aus diesem Grunde sehe ich in meinen Experimenten keine Bestätigung der v. Gudden'schen Erklärung; sie zu widerlegen, wird nur durch zahlreiche, womöglich mit anderen Methoden ausgeführte Experimente gelingen; ein einziges mit negativem Erfolge würde die Frage im Sinne v. Gudden's lösen.

In der Ueberzengung, dass diese Lösung auf dem Wege der Discussion nicht zu erzielen ist, unterlasse ich absichtlich jede weitere Erörterung für die eine oder die andere Auffassung. Nur einen Punkt muss ich noch in Betracht ziehen, um seine Bedeutung für die vorliegende Frage kurz zu beleuchten.

v. Gudden*) hat angegeben, dass beim Kaninchen nach Exstirpation einer Hemisphäre die Nervi optici intact bleiben. Diese Beobachtung kann ich bestätigen. Ueberdies hat Herr Prof. v. Gudden erst kürzlich diese Frage einer gründlichen Revision unterzogen. Die Nervi optici einer kleinen Reihe von 6 Kaninchen, welche alle ganz jung operirt, einer Hemisphäre beraubt waren, wurden möglichst exact

*) Archiv f. Ophthalm. XXV. 1. p. 16.

Archiv f. Psychiatrie. XIII. 2, Heft. 
quergeschnitten, mittelst der Camera obscura bei 23 facher Vergrösserung gezeichnet und je zwei zusammengehörige mit einander verglichen. Wir haben uns dabei überzeugt, dass diese ganze Procedur von Fehlerquellen keineswegs frei ist; die letzteren haben wir möglichst zu vermeiden gesucht und gefunden, dass beim Kaninchen eine nachweisbare Atrophie der Nervi optici in Folge Hemisphärenexstirpation nicht eintritt. Das Kaninchen bietet für die Untersuchung am Nerv insofern ein besonders günstiges Object, als das ungekreuzte Bündel ausserordentlich schwach ist.

Ich habe an der Richtigkeit dieser Thatsache nie gezweifelt; wenn ich ihr aber für die vorliegende Frage eine entscheidende Bedeutung beigemessen hätte, so würde ich meine Experimente überhaupt nicht unternommen haben. Bestimmend war für mich die Erwägung, dass, wenn überhaupt eine reine Atrophie der Nervi optici von der Hemisphäre aus eintrete, diese nur an hochstehenden Säugern nachgewiesen werden könne, deren Grosshirn in mächtiger Verbindung mit den primären Opticuscentren steht. Diese Verbindung geht natürlich nach Hemisphärenexstirpation alle Male und bei allen Thieren zu Grunde; aber je grösser der Antheil ist, welchen sie an der Formirung des Fasernetzes im primären Opticuscentrum nimmt, um so mehr wird man erwarten dürfen, dass die Atrophie derselben sich auch auf jenes System von Fasern ausdehnt, welches unter Vermittlung von Zellen nach der anderen peripheren Seite aus jenem Fasernetze hervorgehend gedacht wird. Dieses Uebergreifen der Atrophie auf die periphere Opticusbahn hatte ich im günstigsten Falle erst bei solchen Thieren als nachweisbar gedacht, deren Hemisphären gegenüber den Reflexe vermittelnden Ganglien eine dominirende Rolle spielen. Somit kann ich in dem abweichenden Befunde, welchen das Kaniuchen mit seinen dürftigen Hemisphären gegenüber Hund und Katze aufweist, nur einen scheinbaren Widerspruch erkennen, der für die Entscheidung der Frage nicht in Betracht kommt.

Ueber das Corpus bigeminum anterius der Säuger verdanken wir Tartuferi*) eine Reihe von Specialuntersuchungen, die gleich ausgezeichnet sind durch die Vorzüge der Methode wie durch die Exactheit der Beobachtung. Insbesondere haben die Verhältnisse des Faserverlaufes durch ihn eine eingehende Berücksichtigung er-

*) Tartuferi, Sull' anatomia microscopica e sulla morfologia cellulare dello ellinenze bigemine dell 'uomo $\theta$ degli altri mammiferi. Gazzetta medica 
fahren. Die Beschreibung, welche Tartuferi von denselben giebt, kann ich, soweit die gleichen Objecte meiner Untersuchung unterlegen haben, im Allgemeinen bestätigen, wenn ich auch in der Deutung einzelner Theile anderer Ansicht bin. Tartuferi gelangte dazu im Corpus bigeminum anter. der verschiedensten Säuger folgende Schichtung nachzuweisen:

1. Zonale Fasern (Fibrille periferiche),

2. Oberflächliches Grau (Cappa cinerea),

3. Oberfächliche aus Fasern und Grau gemischte Lage (Strato bianco cinereo superficiale),

4. Tiefe aus Fasern und Grau gemischte Lage (Strato bianco cinereo profondo),

5. Tiefes oder röhrenförmiges Grau (Grigio centrale),

Untersuchungen, welche ich am Maulwurfe, an der Maus, Fledermaus, Ratte, Kaninchen und Katze angestellt habe, legten mir die Nöthigung auf, diese Eintheilung einigermassen zu modificiren. Wenn ich es hier als nebensächlich ausser Acht lasse, dass ich bei den niederen Säugern (Maus, Fledermaus, Ratte, Maulwurf) zonale Fasern nicht nachzuweisen vermochte, so bestand meine Modification darin, dass ich die 3. Schicht von Tartuferi in drei Abtheilungen zerlegte, nämlich in zwei vorwiegend aus Fasern bestehende und eine zwischen diesen gelegene, vorwiegend graue Schicht, so dass $i \mathrm{ch}^{*}$ ) zu folgender Eintheilung gelangte:

Italiana-Lombardia Serie VIII a. Tom. III. Anno 1877. Diese Arbeit war mir nicht zugänglich.

Derselbe, Le eminenze bigemine anteriori ed il tratto ottico della Talpa europea. Rivista sperimentale di freniatria e medicina legale 1878.

Derselbe, Sull' anatomia minuta dell' eminenze bigemine anteriori delle Scinmie. Revista sperimentale di freniatria e medicina legale 1879.

Derselbe, Contributo anatomico sperimentale olla conoscenza del tratto ottico e degli organi centrali dell' apparato della visione. Torino 1881.

Derselbe, Studio comparativo del tratto ottico e dei corpi genicolati nell' uomo, nella scimmia $\theta$ nei mammiferi inferiori. T'orino 1881 .

Für die freundliche Uobersendung der beiden letzten Arbeiten dem Herrn Verfasser besten Dank.

*) V. Wanderversammlung der Südwestdeutschen Neurologen und Irrenärzte, Bericht in diesem Archiv Bd. XI. p. 278. 1880 und S. Ganser, Vergleich. anatom. Studien über das Gehirn des Maulwurfs im Morphol. Jahrbuch Bd. 7 p. 711. 
1. Zonale Fasern (nur bei höheren Säugern vorhanden),

2. Oberflächliches Grau,

3. Oberflächliches Mark

4. Mittleres Grau

Strato bianco cinereo von Tartuferi,

5. Mittleres Mark

6. Tiefes Mark und

7. Tiefes oder röhrenförmiges Grau.

$\mathrm{Zu}$ dieser Eintheilung bewog mich einmal die relativ gute Abgrenzung der 4. und 5. Schicht bei allen Säugern, dann aber namentlich der Nachweis, dass sie ganz verschiedenen Ursprungs sind. Ich konnte zeigen, dass beim Maulwurfe und bei der Fledermaus entsprechend den dürftigen Sehnerven dieser Thiere das oberfächliche Mark (3) ausserordentlich schwach entwickelt ist, während das mittlere (5) eine mindestens ebenso starke Lage bildet, wie bei anderen Sängern, ein Befund, welcher sich vollständig mit den Ergebnissen deckt, die Herr Prof. v. Gudden nach Exstirpation eines Auges beim Kaninchen erhielt*). Es war somit einerseits der Zusammenhang des oberflächlichen Markes mit dem Tractus opticus, andererseits die Unabhängigkeit des oberflächlichen und mittleren Markes von einander erwiesen und damit die Nöthigung gegeben, sie in der Eintheilung von einander zu scheiden. Es gelang mir endlich sowohl am Maulwurfsgehirn als namentlich überzeugend an schrägen Frontalschnitten durch das Gehirn der Fledermaus nachzuweisen, dass wenigstens ein Theil vom mittleren Marke direct aus der inneren Kapsel stammt.

In einer seiner neuesten Arbeiten hat auch Tartuferi durch Fortnahme eines Auges beim jungen Kaninchen gezeigt, dass die eigentlichen Sehnervenfasern (Fibre visive, Tartuferi) bloss an der Bildung des oberflächlichen Markes sich betheiligen, während er das mittlere Mark (la porzione profonda dell strato bianco cinereo superficiale) aus der Commissura inferior hervorgehen lässt. Ob überhaupt und in welchem Masse die Commissura inferior dem Corpus bigeminum anter. Fasern zuführt, will ich hier nicht untersuchen; davon aber bin ich überzeugt, dass sie am mittleren Mark nicht sehr wesentlich betheiligt ist.

Um die Ergebnisse meiner früheren Untersuchungen einer Controle zu unterwerfen, habe ich einige Experimente angestelllt, über welche ich hier berichten möchte.

Als Objecte wählte ich weisse Ratten, um bei der späteren Be-

*) Vgl. Bericht über die V. Wanderversamml. der Südwestdeutsch. Neurologen u. Irrenärzte in diesem Archiv Bd. XI. p. 279. 
handlung des Gehirnes Osmiumsäure mit sicherem Erfolge anwenden zu können; sind die Objecte gross, so gelingt es schwerer eine Durchfärbung mit diesem Reagenz und vollkommene Schnitte zu erhalten. Für beides sind Rattengehirne noch recht günstig.

Der Ratte A. wurde 3 Tage nach ihrer Geburt das rechte Auge, der Ratte B. in demselben Alter ein Theil der rechten Grosshirnhemisphäre exstirpirt. Die Operationen wurden analog wie bei den Katzen ausgeführt und die Thiere ungefähr nach $3 / 4$ Jahren getödtet.

Bei der makroskopischen Untersuchung der Ratte A, ergab sich der bekannte Befund, der nach Totalatrophie eines Nervus opticus immer beobachtet wird, und der um so auffälliger hervortritt, je vollkommener die Durchkreuzang der Nerven im Chiasma vor sich geht: der linke Tractus opticus war viel dünner und schmaler als der rechte, das Corpus geniculatum laterale und das Corpus bigeminum anterius links flacher und von geringerem Umfange als rechts.

Bei der Ratte B. erstreckte sich der Defect an der Grosshirnhemisphäre ausschliesslich auf den convexen Theil und das Ammonshorn; erhalten waren der Bulbus und Lobus olfactorius, ganz unverletzt das Corpus striatum sammt den übrigen Stammganglien; beide Sehnerven völlig gleich, soweit der Augenschein entscheiden liess; entsprechend der inneren Kapsel zwischen Streifen- und Sehhügel eine tiefe Einsenkung; die rechte Fornixsäule fehlte, von der linken zog ein zartes Markbündel (oberes gekreuztes Bündel der Fornixsäule, v. Gudden) zum Stratum zonale des rechten Sehhügels; der letztere, wie auch die Kniehöcker der rechten Seite zweifellos verkleinert, der rechte vordere Hügel ein wenig abgeflacht; der Pes pedunculi rechts sehr verschmälert, die rechte Pyramide der Medulla oblongata fehlte.

Beide Gehirne wurden der Quere nach in Stücke von mehreren Millimeter Dicke zerlegt, 24 Stunden in 2 procentiger Osmiumsäure gefärbt, in Alkohol vollends gehärtet und mit dem Forel'schen Mikrotome geschnitten.

Soweit das Corpus bigeminum anterius in Betracht kommt, gebe ich die Untersuchungsresultate an der Hand der Fig. 16 und 17.

Fig. 16 einen Schnitt durch den vorderen Zweihügel der Ratte A. darstellend, zeigt links neben einer Verschmälerung des oberffächlichen Grau eine fast totale Atrophie des oberfächlichen Markes, von welchem in der That nur noch Spuren vorhanden sind, während das mittlere Mark beiderseits intact ist. Der Unterschied in den oberflächlichen Markschichten als Effect der einseitigen Bulbusenucleation ist nur bei Thieren mit totaler oder annähernd totaler Kreuzung der 
Sehnerven so gross, wie im vorliegenden Falle. Bei der Katze z. B., welche, wie wir sahen, ein grosses ungekreuztes Bündel besitzt, konnte ich mich an Präparaten der gleichen Darstellungsweise überzengen, dass die Atrophie eines Nervus opticus sich dergestalt auf die oberflächlichen Markschichten beider vorderen Hügel vertheilt, dass kaum eine Differenz wahrgenommen wird. Eine totale Atrophie des oberfächlichen Markes nach ein- oder doppelseitiger Atrophie des Nervus opticus wird man niemals erwarten können, da gerade der hinterste Theil des Tractus eine Menge Fasern fübrt, welche nicht in directem Zusammenhange mit dem Auge stehen, wie dies an anderer Stelle*) auseinandergesetzt wurde. Je mächtiger diese verschiedenen Componenten bei einem Thiere sind, um so grösser wird nach beiderseitiger Bulbusenucleation das Residuum des oberflächlichen Markes sein; bei der Ratte und bei der Maus ist es klein.

Ganz anders ist der Befund bei der Ratte B. (Fig. 17). Hier hat die rechtsseitige Hemisphärenexstirpation das oberflächliche Mark beider Seiten, so viel ich sehe, intact gelassen und nur im mittleren Mark ist rechts eine Atrophie eingetreten. Die Bündel sind hier durchgehends dünner, spärlicher und mehr von grauer Substanz zerklüftet als links und man erkennt auf den ersten Blick, dass eine Menge von Fasern ausgefallen sind. Damit ist der experimentelle Nachweis geliefert, dass das mittlere Mark zum Theile wenigstens aus der Grosshirnrinde abstammt und es könte sich nur noch darum handeln, ob es direct durch die innere Kapsel zum Corpus bigeminum anterius gelangt, oder vor dem Eintritte in das letztere noch eine anderweitige Unterbrechung durch Zellen erfährt, wenn diese Frage nicht durch den Befund am Fledermausgehirne (vgl. oben S. 376) entschieden ist.

Man wird vielleicht annehmen dürfen, dass auch von den erhaltenen Fasern des rechten mittleren Markes ein Theil den gleichen Ursprung in der Hemisphäre hat und zwar in jenen Partien derselben, welche von der Exstirpation ausgeschlossen blieben.

Ob die Atrophie sich auch anf das tiefe Mark erstreckt, welches nach den Untersuchungen von Tartuferi und mir innerhalb der mittleren Markschichte entspringt, ist schwer zu entscheiden, da eine derartige Atrophie wegen des theils gekrenzten theils ungekreuzten Verlaufes der tiefen Markfasern sich auf beide Seiten vertheilen müsste.

*) S. Ganser, Vergl. anatom. Studien über das Gehirn des Maulwurfs, Morph. Jahrb. Bd. 7. p. $703 \mathrm{ff}$. 
Jedenfalls kann ich nicht behaupten, dass der ungekreuzten Fasern im tiefen Marke der rechten Seite auffallend weniger seien als links.

Der schwere Eingriff, welcher bei der Ratte B. stattgefunden hatte, ist die Ursache einer Verkleinerung der ganzen rechten Hälfte des Stammhirnes; wie sehr davon ganz besonders der Fuss des Hirnschenkels und obere Schleife ${ }^{*}$ ) betroffen wurden, ist aus Fig. 16 unmittelbar ersichtlich; genauer auf diese Verhältnisse hier einzugehen, ist nicht meine Absicht, nur auf die Atrophie möchte ich noch hinweisen, welche in dem vom röhrenförmigen Grau des Aquaeductus umschlossenen Faserbündel rechterseits eingetreten ist. Dieses Bündel scheint ans Elementen zu bestehen, welche in weiter vorne gelegenen Ebenen das tiefe Mark in radiärer Richtung durchsetzt haben, im röhrenförmigen Grau sich sammeln und, nach hinten ziehend, sich den Kernen der Augenbewegungsnerven nähern; wegen ihres Verlaufes habe ich früher die Vermuthung ausgesprochen, dass sie eine directe Verbindung der Grosshirnrinde mit jenen Kernen herstellen. Hier scheint wenigstens so viel bewiesen zu sein, dass sie von der Grosshirnrinde abhängen; meine Vermuthung würde ich experimentell für bestätigt halten, wenn es gelänge, nachzuweisen, dass jene Fasern auch von einer Atrophie jener motorischen Kerne secundär in Mitleidenschaft gezogen würden.

\section{Erklärung der Abbildungen. (Taf. VI. und VII.)}

Fig. 1. Horizontalschnitt durch die Papilla nervi optici der Katze: temporale Seite der Retina bei 25 facher Vergrösserung.

ar $=$ area centralis.

$1=$ Nervenfaser- + Ganglienzellenschicht.

$2=$ Innere granulirte + innere Körner-,+ äussere granulirte Schicht.

$3=$ Aeussere Körnerschicht.

$4=$ Stäbchen und Zapfenschicht.

Fig. 2. Durchschnitt der Area centralis der Katze, Ganglienzellen- und innere granulirte Schicht; Vergrösserung S eibert Inm. Syst. 9. 0c. I. Präparat ans der linken Retina der Katze B.

*) Ueber diø Abhängigkeit derselben von der Hemisphäre vgl. v. Gudden: Beitrag zur Kenntniss des Corpus mammillare, dieses Archiv Bd. XI. p. 437 . 
Fig. 3. Basale Ansicht des Gehirnes der Katze A.

Fig. 4. Contur eines Quersehnittes rom Tractus des ungelreuzten Bündels der Katze A. $2 \mathrm{Mm}$. hinter dem Chiasma; etwa 8 fache Vergrösserung (Chromsäure-Alkoholpräparat).

$$
\mathrm{m}=\text { medial, } \mathrm{l}=\text { lateral. }
$$

Fig. 5. Contur eines Frontalschnittes durch den Tractus opticus der Katze A. aus der hinteren Chiasmagegend; der dunkle Streifon entspricht dem atrophischen gekreuzten Bündel.

Buchstaben wie in Fig. 4.

Vergrösserung etwa 8 fach (Chromsäure-Alkoholpräparat).

Fig. 6. Frontalschnitt durch die vordere Chiasmagegend der Katze A.; etwa 30 fache Vergrösserung; Buchstaben wie in Fig. 4, $\mathrm{v}=$ ventral.

Fig. 7. Contur eines Schnitts durch den Nervus opticus (ungekreuztes Bündel) der Katze A.; das atrophirte gekreuzte Bündel ist dunkel gehalten. Vergrösserung 23 fach (Osmiumsäure-Präparat).

$\mathrm{m}=$ medial, $\mathrm{v}=$ ventral.

Fig. 8. Horizontaler Durehsehnitt durch die Eintrittsstelle des Nervus opticus der Katze A. in die Netzhaut, bei 50 facher Vergrösserung.

$\mathrm{t}=$ temporal.

$\mathrm{n}=$ nasal.

$1=$ erhaltene Nervenfaser- und Ganglienzellensohicht.

$l^{\prime}=$ atrophische

Die übrigen Ziffern wio in Fig. 1.

Fig. 9. Stelle ans der temporalen Netzhauthälfte der Katze A.; die drei inneren Schichten, gezeichnet bei $\mathrm{S} \theta \mathrm{i}$ bert Imm.-Syst. 9 Oc. I.

Fig. 10. Stelle aus der nasalen, atrophischen Netzhanthälfte der Katze A., die drei inneren Schichten, gezeichnot bei Seibert. Imm.-Syst. 9 Oc. I.

Fìg. 11. Gegend des Chiasma und Tractus opticus eines Epileptikers; das ungekreuzte Opticusbündel verläuft rechts isolirt.

Fig. 12. Dorsale Ansicht des Gehirns der Katze B.; natürl. Grösse.

Fig. 13. Basale Ansicht desselben; natürl. Grösse.

Fig. 14. Conturen von Querschnitten beider Nervi optici der Katze B. Die grössere Contur ist die des linken Sehnerven; die dunkle Sichel die Differenz beider Querschnitte; 23 fache Vergrösserung.

Fig. 15. Drei Conturen von Sehnervenquerschnitten; die kleinste Contur entspricht dem linken, die mittlere dem rechten Nervus opticus der Katze C.; die Differenz ist schwarz gehalten; die grösste Contur entstammt einem Sehnervenquerschnitte einer mit C. gleichalterigen, hier als normal zu betrachtenden Katze; Vergrösserung 23 fach.

Fig. 16. Frontalschnitt durch das Corpus bigeminum anterius der Ratte A. (rechtes Auge enuoleirt), aus einer Serie von Osmiumpräparaten, etwa 12 fach vergrössert. 
o. G. $=$ oberflächliches Grau.

o. M. $=\quad$ Mark.

m. G. = mittleres Grau.

m. M. $=\quad, \quad$ Mark.

t. M. $=$ tiefes Mark.

t. G. $=$ tiefes Grau.

$\mathrm{x} .=$ Faserbündel, welches wabrscheinlich durch Vermittlung des mittleren Markes aus der inneren Kapsel kommt und zu den Kernen der Augenbewegungsnerren gelangt.

Fig. 17. Frontalschnitt durch das Corpus bigeminum der Ratte B. (rechte Grosshirnhemisphäre theilweise exstirpirt); aus einer Serie von Osmiumpräparaten in der Gegend der vorderen Oculomotoriuswurzeln und des rothen Kernes der Haube; 12 fach vergrössert.

Bezeichnungen wie in Fig. 16.

München, im April 1882. 
है
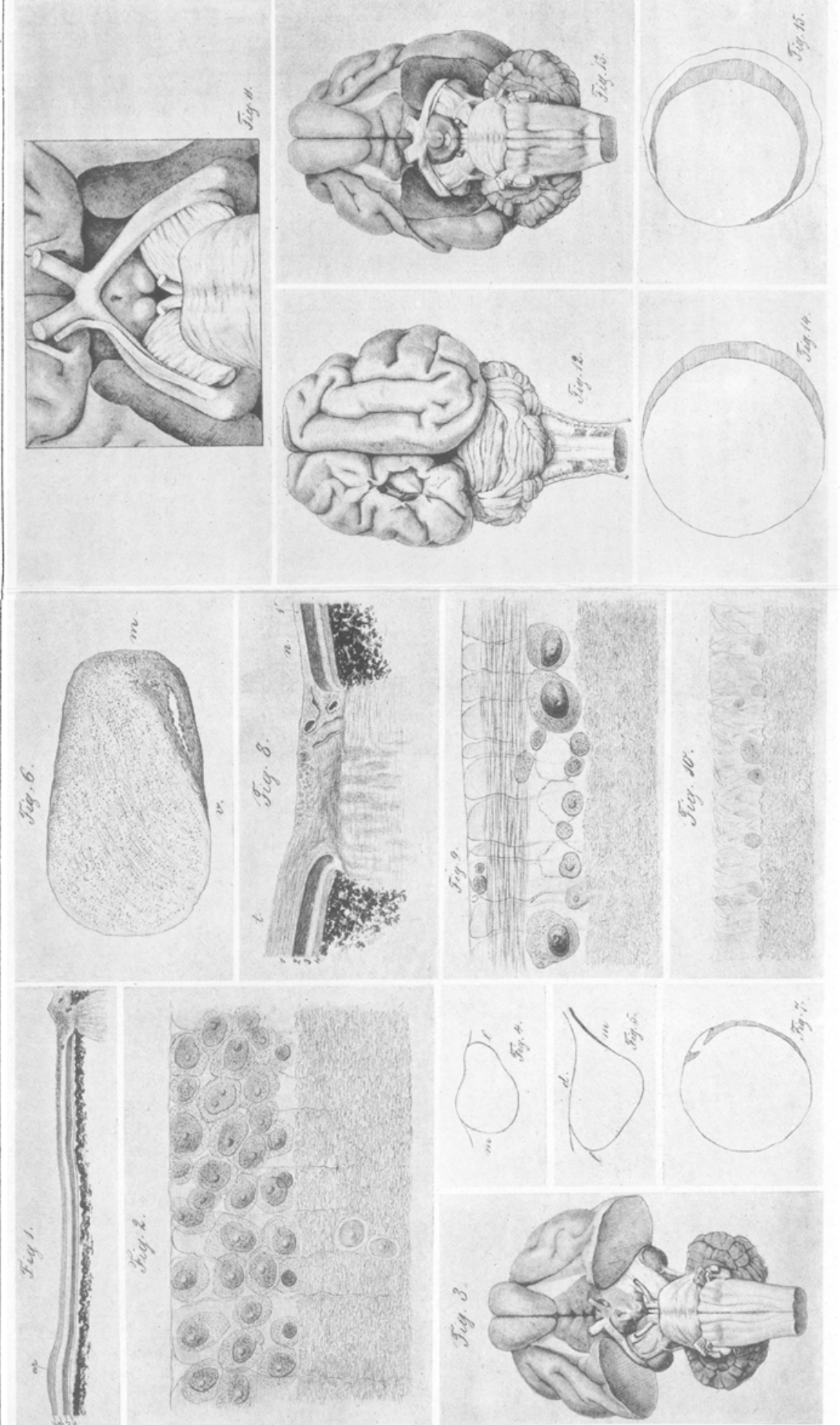
Archis für Psychiatrie etc. Bd. XIII.

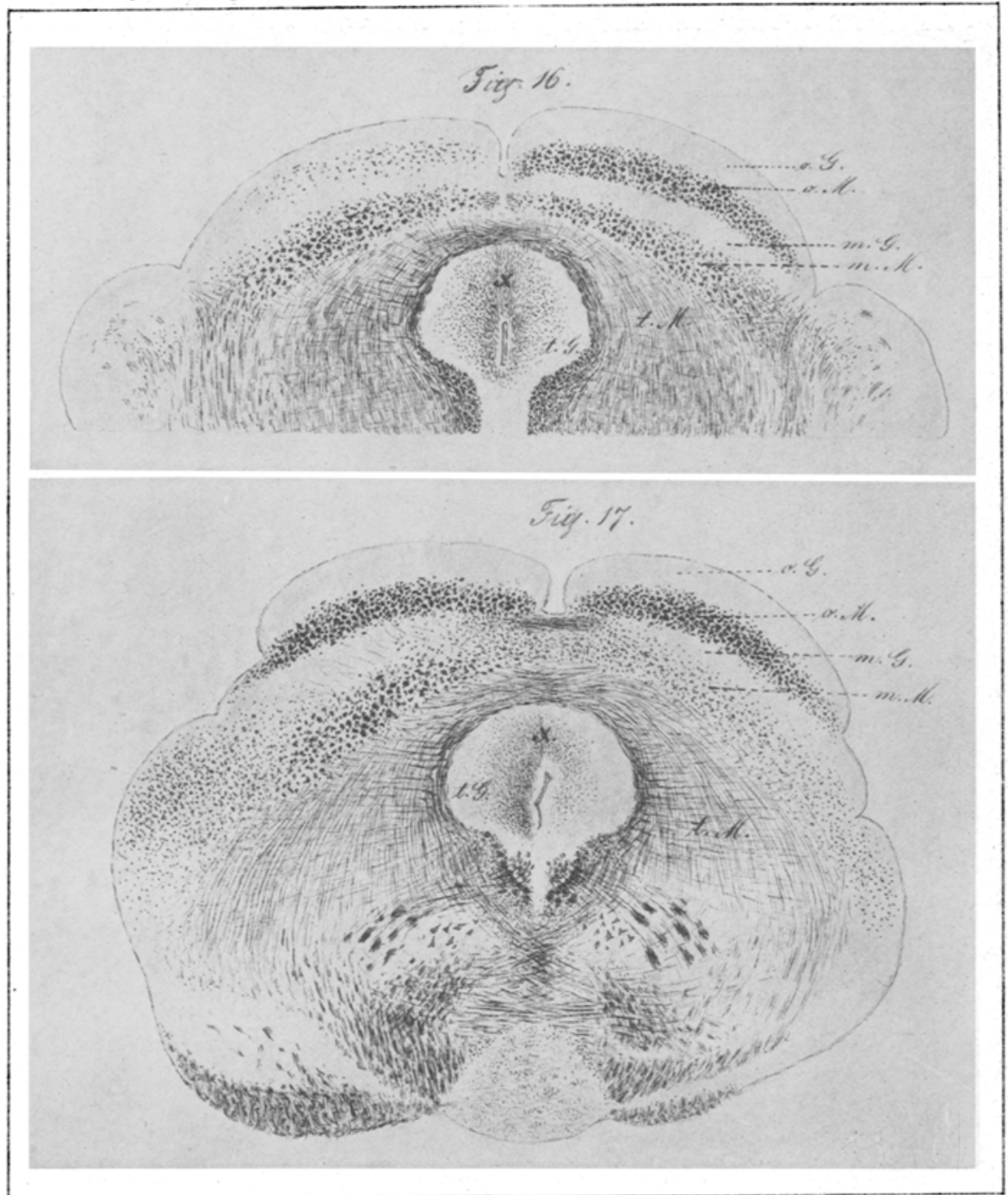

Lichtdruck o. Gemoser, Munchen 